Disease Environment and Civil Conflicts

Matteo Cervellati, Uwe Sunde, Simona Valmori

April 2011 Discussion Paper no. 2011-13

School of Economics and Political Science,

University of St. Gallen

Department of Economics 


$\begin{array}{ll}\text { Editor: } & \text { Martina Flockerzi } \\ & \text { University of St. Gallen } \\ & \text { School of Economics and Political Science } \\ & \text { Department of Economics } \\ & \text { Varnbüelstrasse } 19 \\ & \text { CH-9000 St. Gallen } \\ & \text { Phone } \quad+41712242325 \\ & \text { Fax } \quad+41712243135 \\ & \text { Email seps@unisg.ch } \\ & \text { School of Economics and Political Science } \\ & \text { Department of Economics } \\ & \text { University of St. Gallen } \\ & \text { Varnbüelstrasse 19 } \\ \text { Publisher: } & \text { CH-9000 St. Gallen } \\ & \text { Phone +41 71 224 23 25 } \\ & \text { Fax } \quad+41712243135 \\ & \text { http://www.seps.unisg.ch }\end{array}$




\title{
Disease Environment and Civil Conflicts ${ }^{1}$
}

\author{
Matteo Cervellati, Uwe Sunde, Simona Valmori
}

Author's address:

Matteo Cervellati

University of Bologna and IZA, Bonn

Email m.cervellati@unibo.it

Prof. Dr. Uwe Sunde

SEW-HSG

Varnbüelstrasse 14

Phone +41712242309

Fax +41712242302

Email uwe.sunde@unisg.ch

Website www.sew.unisg.ch

\author{
Simona Valmori \\ University of Bologna \\ Email simona.valmori@unibo.it
}

\footnotetext{
${ }^{1}$ We thank seminar participants at Universities of Bologna, Freiburg, Modena, the Zurich Workshop on the Economics of Conflict, the Workshop on Conflict and Development in Namur, the Workshop on the determinants of Civil Conflicts in Madrid, and SCALA - University of St.Gallen for helpful comments. We also thank Markus Brückner, Joan Maria Esteban, Bernd Fitzenberger, Margherita Fort, Eliana la Ferrara, Gerard Padro-i-Miquel, Adam Przeworski, Debraj Ray, Dominic Rohner, Mathias Thoenig, and Fabrizio Zilibotti for detailed suggestions. We are grateful to Jean-Francois Guegan for sharing with us the data on the richness of infectious diseases and to Centre for Research on the Epidemiology of Disasters (CRED) for supplying the data on natural disasters.
} 


\begin{abstract}
This paper tests the hypothesis that a high and persistent exposure to infectious diseases increases the likelihood of civil conflicts. Diseases that are difficult to prevent and treat may reduce the opportunity costs of violent activities, both directly and indirectly. The analysis exploits new data on the number of multi-host vector-transmitted infectious diseases that are endemic in each country. As consequence of their specific features, the presence of these pathogens in a country is closely related to geo-climatological conditions and exogenous to civil conflict. The findings document that a larger disease richness is a statistically robust and quantitatively relevant determinant of civil conflicts for the period 1960-2004. Exploiting within country variation, the findings also document that interactions between climatological shocks in terms of droughts and the disease environment have a significant effect on the risk of civil wars. The results are robust to different specifications, data sets and estimation methods, and suggest that the persistent exposure to a more unfavorable environment in terms of disease richness is an important determinant of the incidence of civil conflict. The results also suggest the potential relevance of a channel linking geography to economic development that has not been investigated in the literature.
\end{abstract}

\title{
Keywords
}

Disease Environment, Civil Conict, Multi-Host Vector-Transmitted Pathogens, Civil War.

\section{JEL Classification}

D74; J1 


\section{Introduction}

Civil conflicts are the most common warfare events in the last fifty years and account for the largest number of conflict-related casualties. At the same time, they cause large social and economic disruption. A growing empirical literature investigates the determinants of civil conflict and has pointed out several relevant factors that increase the risk of civil conflicts. These factors include geographic conditions that favor insurgency, poor economic living conditions in terms of per capita income and income growth, ethnic polarization, the presence of lootable natural resources, deficient economic and political institutions, and the occurrence of climatological shocks ${ }^{1}$

This paper complements this literature by providing a first systematic investigation of the role of the disease environment as a potential determinant of civil conflicts on the basis of a novel measure of exogenous, persistent disease exposure. Poor health conditions have been shown to affect important socio-economic outcomes $\mathrm{2}^{2}$ The literature has pointed out several, not mutually exclusive, arguments that suggest that a permanent exposure to deadly diseases and a difficult health environment could also be relevant for violent social conflicts. It has been argued extensively that bad living conditions may breed violent conflicts, but this hypothesis has typically been tested using information on income per capita or income per capita growth. Individual health conditions, the exposure to fatal diseases, and mortality rates are potentially even more important determinants of individual living conditions and well-being than income, however. At the same time, differences in health conditions and mortality across countries are often larger than the respective differences in income per capita. $3^{3}$ The argument that income per capita is an insufficient and often misleading measure of individual well-being and

\footnotetext{
${ }^{1}$ Empirical studies on the determinants of civil conflict have mostly exploited cross-country panel data, as in Fearon and Laitin (2003), Collier and Hoffler (1998, 2002, 2004), Montalvo and Reynal-Querol (2005b), and Collier, Hoeffler and Rohner (2009). Other studies have exploited within country variation, such as Miguel and Sergenti (2004), Ciccone (2009), Besley and Persson (2009, 2011). See also Blattman and Miguel (2010) for a survey of the stylized facts on civil conflicts and a comprehensive survey of the empirical literature.

${ }^{2}$ For instance, Bleakley (2007), Bleakley and Lange (2009) and Jayachandran and Lleras-Muney (2009) provide evidence that better health and higher life expectancy increase individual educational attainments. At the macro level, the empirical role of life expectancy for human capital and growth has been investigated by Soares (2005) and Lorentzen, McMillan and Wacziarg (2008), while settler mortality has been shown to influence economic outcomes through the adoption of institutions, see Acemoglu, Johnson, and Robinson (2001).

${ }^{3}$ For instance, most underdeveloped countries face very high infant mortality rates of more than 30 percent, which is almost one hundred times larger than the average infant mortality rates of 0.4 percent in the most developed countries. Life expectancy in the countries with the lowest levels is at the order of about 0.3 the countries with the highest level of life expectancy at birth. The respective relation between log income per capita is around 0.5.
} 
quality of life has been made frequently in the literature 4 An implication that has received less attention is that individuals with poor health and high mortality rates may face a lower opportunity cost of getting involved in activities that put their health, or life, at risk $5^{5}$ The literature has also documented that the persistent exposure to poor health conditions and high mortality discourages long-term productive investments like, for instance, the acquisition of human capital, see, e.g., Soares (2005), or the related literature on predatory versus productive investments, see, e.g., Grossman and Kim (1995) ${ }^{6}$ In the context of civil conflicts, a lower opportunity cost of violence may therefore lead to lower thresholds for violent activities (in the sense of predatory rather than productive activities), and may also materialize in facilitating the recruiting of rebels and mercenaries. If these long term productive investments substitute, or increase the opportunity cost of, violent activities, then a better health environment should reduce the risk of civil conflicts. In a broader and longer term perspective, a permanent exposure to a harsher disease environment may increase the risk of civil conflicts by shaping the organization of societies like, for instance, by leading to the adoption of deficient economic and political institutions 7 Finally, the literature in economic development and epidemiology suggests that the disease environment might also exacerbate the negative effects of climatological shocks like the occurrence of droughts. Extensive periods of exceptionally low precipitation and high temperature do not only represent negative shocks to economic well-being, but also lead to water shortages, cause famines and deteriorate sanitary and hygienic conditions. The effect of such weather shocks on triggering civil conflicts may therefore be magnified in an environment with a large and persistent exposure to potentially deadly infectious diseases.

In general, identifying the empirical role of the disease environment for socio-economic outcomes

\footnotetext{
${ }^{4}$ This has led to the incorporation of longevity into assessments of cross-country inequality (see, e.g., Becker et al., 2005 ) and the consideration of life expectancy as one of the central components of the UN Human Development Index.

${ }^{5}$ Large mortality rates have been shown to be associated with riskier behavior and increased involvement in activities that pay-off in the short run. For instance, exogenously large mortality rates (like e.g. having been exposed to extreme events like the accident to the nuclear plant at Chernobyl in 1986) substantially increased death rates related to smoking, drinking and car speeding, the practice of unsafe sex and the spread of HIV, see Lorentzen, McMillan, and Wacziarg (2008). Similarly, the experimental findings by Lammers and van Wijnbergen (2008) show that HIV positive South African students, and individuals that perceive to have a high risk of contracting HIV are less risk-averse and display larger discount rates.

${ }^{6}$ In this context, weak institutions that do not provide full security of claims to property or income can be seen as substitute to longevity in the sense of the physical ability to appropriate the rents of investment activities in the future.

7 This is in line with the argument proposed by Acemoglu, Johnson, and Robinson (2001) on the role of mortality of European settlers for the quality of institutions that they established in the colonies.
} 
has proved a difficult task and their role for civil conflict is still unexplored. A problem in addressing this issue is that health outcomes for which data are available depend on both the exogenous (country specific) exposure to fatal diseases, but also on economic development and socio-economic conditions. For instance, income per capita, the level of education, demo-economic outcomes, the health infrastructure and civil conflicts affect mortality rates, the prevalence of different diseases, and the general health conditions ${ }^{8}$ The literature has therefore sought to exploit exogenous variation in local geo-climatological conditions (often in terms of latitude, temperature and precipitation), since these conditions are important determinants for the survival and reproduction of pathogens, their hosts, as well as their transmission vectors. Using information on geo-climatological conditions as proxy for differences in mortality and disease environment has important limitations, however, since these conditions are very likely related also to other relevant factors, most importantly endogenous institutions and economic development. A more refined, but conceptually similar, strategy involves using exogenous geo-climatological conditions as instruments for health outcomes. The applicability of this approach to study civil conflicts is prevented by the lack of relevant and plausible instruments for the disease environment that satisfy the exclusion restriction. As documented by much of the available literature, the geo-climatological conditions may have direct effects on the risk of civil conflicts beyond affecting the disease environment.9

In this paper, we devise a different empirical strategy to study the role of the disease environment for civil conflict. This strategy relies on the use of newly available data on the spatial distribution of all infectious disease pathogens for humans that have ever been detected, or that are endemic, in a country. We use this information to create indices of extrinsic disease richness for each country that are, by construction, exogenous to civil conflict incidence, economic development, or other typical confounds. The raw data have been collected for medical purposes and for the monitoring of the spread of diseases and are made available in the database supplied by the Global Infectious Disease and Epidemiology Network, GIDEON 10 As discussed in more detail in Section 2, infectious agents

\footnotetext{
${ }^{8}$ See, e.g., Mirovsky and Ross (1998), Smith (1999), Wang (2003), van den Berg et al. (2006), Cutler et al. (2006), among others. This literature has also pointed out that the data on aggregate health outcomes suffer from serious measurement problems, in particular in developing countries, where the data is often little informative on actual morbidity and health conditions.

${ }^{9}$ The strategy of using geographical information as instrument for health outcomes has been fruitfully applied to study the role of life expectancy for income per capita growth by Lorentzen, McMillan and Wacziarg (2008). For conflicts as outcomes, however, the exclusion restriction is very unlikely to hold in view of the literature.

${ }^{10}$ This dataset provides a monthly update on information for more than 300 human infectious agents in more than 200 countries. The data are available upon subscription at http://www.gideononline.com.
} 
affecting humans can be classified by two dimensions: their hosts and their transmission channel. Hosts, which are the reservoirs in which the pathogens multiply and grow, can be humans, animals or plants (zoonotic hosts), or several of those (multi-host pathogens). The transmission can be direct, from human to human like AIDS or influenza, or only through a vector, like mosquitoes. This information on hosts and transmission channels has been used recently by micro-biologists and ecologists to study the determinants of the world distribution of human pathogens. A particularly interesting finding for the purposes of this paper is that the world-wide distribution of infectious agents in the class of multi-host vector-transmitted diseases (MHV, henceforth), which includes some of the most important human killers is most closely related to the particular local conditions and is affected least by dynamic events like globalization ${ }^{11}$ The reason is that the pathogens of the class of MHV diseases use both humans and non humans as host reservoirs, but can be transmitted to humans only through some specific transmission vectors. This means that these pathogens require particular geo-climatological conditions for the transmission vectors (like mosquitos) to reproduce and spread, which prevents their endemicity in non suitable environments 12 At the same time, the fact that these pathogens are hosted by multiple reservoirs, both human and non-human, represents a serious impediment to their control and eradication 13 Taken together, these features imply that whether a MHV pathogen is endemic in a country is mostly determined by geo-climatological conditions 14 The permanent exposure to the risk of infections (which often lead to death) that lies largely outside the control of individuals, also often materializes in passive and fatalistic attitudes in the affected populations regarding the chances to survive to old age. In view of their serious health consequences coupled with the very limited success in control and eradication at the national, at the regional or sub-regional level, the MHV diseases are considered a top priority by the WHO. This is reinforced by

\footnotetext{
${ }^{11}$ This is documented in particular by Guernier et al. (2004) and Smith et al. (2007). We discuss these issues in more detail in Section 2 .

${ }^{12}$ On the contrary pathogens that can be transmitted from humans to humans directly tend to be more uniformly spread across countries. For instance HIV is currently endemic in all countries of the world.

${ }^{13}$ The specific features imply that the infectious agent needs to be controlled and eradicated in all hosts (that often include remote sylvatic species). This seriously limits the development and use of vaccines, which are in fact generally not available (yet) for MHV diseases. This is one of the reasons why MHV diseases represent some of the major killers, and why these diseases are resurgent in serious epidemics even after extensive periods of treatment and control. In contrast, for single-host non-vector transmitted human diseases, like influenza, the development of effective treatment, control and vaccination is comparably easy, which even led to the eradication of some of the diseases of this type, as discussed in more detail below.

${ }^{14}$ Endemicity refers to the presence of a pathogen in a country without need of external inputs as discussed in Section 2
} 
the fact that the spread of these diseases, which is essentially driven by climatological conditions, is expected to increase in the next decades as consequence of global warming, which enlarges the areas suitable for the vectors.

The empirical analysis exploits information of whether a particular MHV pathogen has ever been detected or, alternatively, whether it is endemic in a country. The analysis does not exploit information on the current spread or prevalence of these diseases within a country. This delivers a conservative measure of the actual disease exposure since it provides a comparable measure regardless of whether a country has no functioning health system or a country where the diseases are nominally present but treatment facilities are good and the disease spread is under fairly close control. This empirical strategy has the advantage that the mere presence, or endemicity, of a pathogen in a country essentially depends on the exogenous local geo-climatological conditions. But rather than proxying these conditions, the measure uses actual documented counts of diagnosed disease pathogens as measure of disease exposure. Together with the fact that eradication was not possible for diseases of this type, this implies that MHV pathogens have features that are very convenient for purposes of this paper. Contrary to the data on health outcomes or the actual spread and prevalence of each of these diseases, the information on the worldwide distribution of the "number" of MHV agents in each country is conceptually unrelated to the incidence of (localized) civil conflicts. Given their importance, the MHV diseases are carefully monitored also in developing countries, such that the information on their mere presence in a country is subject to much lower measurement error than information on the actual prevalence of the diseases. The number of endemic pathogens of the class of MHV that are observed in a country therefore provides a time invariant, admittedly rough, but conservative and relevant novel measure of the differences in the extrinsic exposure to (serious) infectious diseases across countries.

The paper investigates whether the extrinsic disease environment has an effect the incidence of civil conflicts. The main variable of interest is the incidence of conflicts of intermediate and high intensity ${ }^{15}$ The analysis applies the typical specification in the empirical literature on the determinants of conflict, with a binary dependent variable indicating whether a conflict is observed or not during the period 1960-2005, where the data are coded in five year intervals in the benchmark specification. The analysis controls for region specific effects, includes dummies for small regions (of about ten countries on average), and controls for period fixed effects. Exploiting this within-region variation,

\footnotetext{
${ }^{15}$ These are the civil conflicts resulting in at least 25 battle-related deaths per year with a cumulative total number of deaths larger than 1,000 which are classified as civil wars by in the PRIO data set. We postpone to Section 2 a detailed description of the different specifications, dependent variables and co-variates.
} 
the results document that the exposure to a large set of MHV diseases is an important determinant of the incidence of civil conflicts. The effect is statistically very robust and quantitatively important across different specifications. In the baseline specification, the estimates imply an increase of 5.7-7.5 percentage points in the likelihood of conflict incidence for a one-standard deviation increase in disease richness. With an unconditional probability of conflict of around 16 percent, this corresponds to an increase of 35-46 percent. The findings are confirmed with different alternative indices of disease richness, alternative definitions of civil conflicts, alternative econometric specifications, including random effects estimations, and when using alternative data frequencies (annual or cross-sectional data). The results are robust to the inclusion of a full set of economic, demographic, institutional and geographical controls that have been proposed in the literature, as well as to the inclusion of additional geographical controls. The role of the disease environment emerges also when restricting attention to developing countries, or former colonies, or to the sub-sample of African countries. This suggests that the disease environment is an important determinant of conflict even among countries with similar levels of development.

As a further contribution, the analysis investigates the potential interaction effects between the disease environment and climatological disasters in terms of occurrence of periods of droughts, for the incidence of civil war. This analysis exploits within country variation overtime by including country fixed effects. The results document a significant positive interaction effect between disease richness and the occurrence of droughts on the incidence of civil conflict, which suggests that these climatological shocks are more likely to lead to civil conflicts in countries that exhibit a large exposure to MHV diseases. These results hold when accounting for time invariant country heterogeneity, year fixed effects, and are robust to the use of alternative measures of disease environment and civil conflicts, the inclusion of the typical control variables, alternative econometric specifications (including both fixed and random effects models) and alternative data frequencies (annual and five years intervals).

The paper is structured as follows. Section 2 describes the data and the empirical strategies. The results are reported in Section 3 while Section 4 concludes.

\section{Data and Empirical Strategy}

Background: Multi-Host Vector-Transmitted Diseases. The analysis relies on information about the spatial (cross-country) distribution of multi-host vector-transmitted (MHV) infectious diseases. This class of infectious diseases affecting humans has particular features that make them 
very useful for the purposes of this paper.

First, MHV infectious disease pathogens are affected little by globalization, in terms of migration of infected humans, economic activities or trade. In fact, these infectious disease agents are the least globalized class of diseases with humans as reservoir, as documented by Guernier et al. (2004) and Smith et al. (2007). Their main finding indicates that climatic factors are of primary importance in explaining the link between latitude, temperatures, and the spatial distribution of human pathogens, especially of the class of MHV diseases. The main reason is that these pathogens are transmitted from human to human only through particular vectors. The prevalence of these diseases in terms of endemicity in a country thus relies on the existence of the specific local geographic, climatic and biological conditions that are required by the vectors to survive, reproduce and spread. This feature implies in particular that, differently from non vector-transmitted diseases like, e.g., HIV-AIDS or influenza, a MHV pathogen cannot be endemic in countries unless the specific vector is present and finds sufficiently suitable geo-climatological conditions to reproduce. ${ }^{16}$

Second, the fact that infectious disease agents of this class grow in multiple host reservoirs (humans as well as animals) makes them very difficult to control and has represented a serious impediment for the success of the campaigns of their eradication. Even the treatment or vaccination of all infected humans may not be sufficient for a complete eradication, since the pathogen would have to be eradicated from all hosts. Moreover, vaccines are generally not available for MHV diseases ${ }^{17}$ In fact, none of the MHV deadly diseases have been successfully eradicated at the regional or sub-regional level, and neither is any of the MHV deadly diseases expected to be eradicated in the near future. Tables 1 and 2 report information on the possibility of treatment and eradication for the MHV diseases 18 Some countries have managed to limit or control the spread of MHV diseases within their territory, but not up to the point of full eradication 19 As consequence, the MHV pathogens have

\footnotetext{
${ }^{16}$ This becomes evident from the fact that around 90 percent of pathogens that use only humans as reservoirs and that are transmitted directly are present in more than 90 percent of the countries, whereas the respective figure for MHV pathogens is less than 10 percent. We refer to Cervellati, Sunde and Valmori (2011) for a detailed analysis of the spatial distribution of human pathogens of the different classes and their relevance for health outcomes.

${ }^{17}$ Exceptions are Yellow fever and Thypus-Epidemic for which vaccines are available even if, especially for Yellow Fever, the vaccine is difficult to administer and heat sensitive, while no cure is currently available.

${ }^{18}$ The main sources of information are the GIDEON database, the World Health Report (2008), freely available online at http://www.who.int/whr/2008/whr08_en.pdf, and the report of the International Task Force for Disease Eradication (1993 updated in 2008) whose summary results are available at:

http://www.cartercenter.org/resources/pdfs/news/health_publications/itfde/updated_disease_candidate_table.pdf.

${ }^{19}$ Even in countries like the US diseases like Dengue and Yellow Fever are still endemic in some parts of the country (mainly located in the South).
} 
been resurgent in serious epidemics even after lengthy periods of extensive treatment and apparent control of their geographical spread in some countries.

Third, vector-born diseases are relevant determinants of health both directly and indirectly. From the 17 th until the early 20th Century, vector-borne diseases were responsible for more human deaths than all other causes combined (including civil and international wars), and are responsible for large deadly epidemics still today see, e.g., Gubler (1991). Given their relevance the MHV are closely monitored, especially in the most developed countries. The literature in epidemiology and the WHO have issued warnings on the resurgence of diseases like dengue and yellow fever based on the fact that the areas that are potentially suitable for the vectors to reproduce are increasing as consequence of global warming, see e.g. Gubler (1998) and Stanley et al. (2008).

Finally, information on the disease burden and richness in terms of MHV pathogens is not only interesting per se, but can be informative in a broader sense about the cross-country differences on the overall exposure to human infections diseases. This is the case for several reasons. A large richness of MHV diseases indicates a generally high exposure to several non-vector transmitted diseases as well. The main reason is that geo-climatological conditions favoring the endemicity of MHV are also a favorable environment for the other pathogens 20 In fact, the countries with the highest richness of MHV diseases account for about two thirds of the countries with the highest number of all other human pathogens ${ }^{21}$ Another aspect is that there is increasing evidence that MHV diseases are important biological co-factors for other diseases. They increase, for instance, the vulnerability to an HIV infection and the contagiousness of infected persons, thereby increasing the probability of transmission 22

In summary, the presence of a large number of MHV diseases in a country is therefore a relevant indicator of local geo-climatological conditions that imply a high disease richness and extrinsic exposure to diseases that influences human health both directly and indirectly. The richness of MHV diseases in a country is also informative about the exposure to other relevant human diseases. For these reasons, the worldwide spatial distribution of multi-host vector transmitted pathogens pro-

\footnotetext{
${ }^{20}$ For instance, countries hosting dengue are likely to have been exposed also to malaria since the pathogens of these two diseases can be transmitted by the same mosquito (Aedes Aegypti), and yellow fever. More specifically, the climatological conditions favoring the bio-diversity of human pathogens in this class favor the bio-diversity in the other pathogens classes as well as documented by Smith et al. (2007).

21 For instance, out of the countries in the highest quartile in terms of MHV, 65 percent are also in the highest quartile of all other human pathogens. The richness of MHV diseases is a significant predictor of several types of health outcomes and of the risk of observing different types of epidemics (see also Cervellati, Sunde and Valmori, 2011).

${ }^{22}$ See Gopinath et al. (2000) and Karp and Auwaerter (2007) and references therein.
} 
vides relevant and new information about the cross-country differences in the exogenous exposure to human diseases.

Data on Multi-host vector transmitted pathogens. The data on the presence of human infectious diseases across countries have been used by Guernier et al. (2004) and Smith et al. (2007) to investigate the role of environmental factors for the biological diversity of human pathogens and their worldwide distribution. The data have been extracted from the GIDEON database. As discussed above, human infectious agents can be classified according to their reservoir and their transmission channel. In terms of reservoir, the pathogens can be classified as Human only (like HIV) if the pathogen has humans as only reservoir for the sickness, Zoonotic (like plague or anthrax) if the reservoir of the pathogen is exclusively an animal or a plant, or multi-host if the pathogen uses both humans and non-humans as reservoir. In terms of transmission channel, the diseases can be classified depending on whether the pathogen is transmitted directly from human to human (like e.g. HIV-AIDS, or influenza), or whether humans can be infected only through a vector (like the mosquito Aedes Aegypti for dengue) ${ }^{23}$

For the analysis below, we use information on the number of MHV infectious agents that have ever been observed in each country as measure of disease richness. We analyze several alternative measures by restricting attention to different types of MHV agents. The benchmark explanatory variable, called "Disease Richness (Deadly)", represents the number of multi-host vector transmitted diseases with a significant risk of death. These diseases are Dengue, Yellow Fever, Leishmaniasis Visceral, Relapsing Fever, Typhus Epidemic, Trypanosomiasis Africanis. Between zero and six of these disease agents are observed in a given country. ${ }^{24}$ The main characteristics of these diseases, including the pathogen type, fatality and availability of vaccines, are summarized in Table 2, As an alternative measure, we also have recoded the disease richness variable by collecting data on the current endemicity of the deadly multi-host vector-transmitted diseases from the GIDEON database. Each of the fatal MHV diseases is coded to be present in a country only if is endemic, that is, if the infectious agent is maintained in the population without the need for external inputs. ${ }^{25}$ The recoded

\footnotetext{
${ }^{23}$ The full classification of human diseases including the infectious agent, the taxonomic group, the reservoir hosts, the vector hosts and the host category is available from the Ecological Archive E88-114-A1 at: http://esapubs.org/Archive/ecol/E088/114/appendix-A.htm .

${ }^{24}$ We include relapsing fever in the subset of potentially deadly diseases since the probability of death is between 30 and 70 percent if not treated, although it is around 1 percent if treated.

${ }^{25}$ More specifically, a disease is in an endemic steady state if the basic reproduction rate of the infectious agents in the population times the share of non immune population equal one. Evaluating the endemicity requires discounting
} 
variable is labeled "Disease Richness (Endemic)".

In general, indexes constructed using information on whether a disease has ever been observed in a country or whether it is (currently) endemic may be quite different if the disease has been eradicated in some of the countries, or if it spreads across countries overtime. The benchmark index that codes diseases according to whether the disease has ever been observed in a country delivers a more conservative measure of the exposure to these diseases in the poorest countries compared to the coding based on endemicity. The reason is that a disease is counted in a country if it has ever been observed, even if the spread of the disease is actually very limited. The measure Disease Richness (Endemic) contains the same diseases as the benchmark measure, Disease Richness (Deadly), but with the difference that a disease is counted as being present in a country only if it is currently endemic, and not if it has ever been observed (without necessarily being endemic today). This difference in coding implies that the endemic index is potentially affected by successive campaigns of disease eradication, which might be related to socio-economic development. The difference between the different codings turns out to be immaterial for the deadly MHV diseases, however. In fact, precisely for their specific features, the difference between the two indices of disease richness constructed using different coding is small ${ }^{26}$ This is to be expected given the difficulty to control and eradicate these diseases, and the role of local conditions, which imply that if a pathogen was ever observed in a country then it is also likely to be currently endemic due the time invariant local geo-climatological conditions favoring the reservoirs and vectors. In particular, the baseline index Disease Richness (Deadly) is conceptually unrelated to the level of development and the effectiveness of treatment in a country, because it only uses information on the presence of the pathogen in a country instead of the actual prevalence of the disease in terms of the number of infected individuals, and since none of these pathogens has been successfully eradicated at the sub-regional level.

For robustness we also consider a broader measure of disease richness, "Disease Richness (MHV)", which includes all multi-host vector-transmitted diseases irrespective of their degree of fatality. Apart from the subset of deadly pathogens listed above this measure includes angiomatoses, filariasis-brugia the immune share of the population. The data on the endemicity of MHV deadly diseases are extracted from the GIDEON database updated to July 2009.

${ }^{26}$ There are very few differences in the coding of "Disease Richness (Deadly)" and the "Disease Richness (Endemic)". These differences mainly refer to the exclusion of a small number of cases of diseases that have been recorded to be observed but that are coded as not endemic. These cases are mainly related to tourists or workers returning to the country from travels abroad, which are included in the GIDEON dataset and coded as ever detected in a country by Guernier el al. (2004). The correlation between the two variables "Disease Richness (Deadly)" and "Disease Richness (Endemic)" is 0.98 . 
malayi, leishmaniasis (mucocutaneous and cutaneous), malaria, onchocerciasis and trypanosomiasis (American sleeping sickness). Between zero and eleven of these diseases are observed in a given country. Table 1 reports information on the full set of MHV diseases, including the global distribution of the pathogens, the possibilities of their eradication and summary information on their prevalence. For some of the diseases in the broader set of MHV Disease Richness (MHV) eradication and effective control may be more of an issue. Specifically, Malaria has been successfully treated, or even eradicated, in some of the more developed countries.27 Also, some of non-fatal MHV diseases are observed only infrequently in the more developed countries. In particular, Filariasis-Brugia Malayi and Onchocerciasis (River Blindness) are observed in relatively few countries and have also been subject to successful campaigns or eradication at the local (or sub-national) level. To deal with this issue, we rely on the coding based on the criteria whether the disease has ever been detected in each country even if it is currently not endemic or even eradicated when constructing the disease richness for the full MHV category ${ }^{28}$ This provides another reason (on top of the fact that we do not rely on information on the current prevalence in terms of spread) why this index is likely to underestimate the actual burden of diseases in the poorest countries. Finally, as a robustness check, we perform the analysis by iteratively excluding each of the diseases to control for the possibility that the results are driven by specific pathogens.

Recall that the measures on disease richness are based on data which record whether or not a specific disease exists in a country, and not its actual or current spread or prevalence. These features have pros and cons. Irrespective of whether the coding is based on the consideration of the number of diseases that has ever been observed in a country or the number of diseases which are currently endemic, the resulting indices of disease richness are time invariant and contain no information about the actual current prevalence of each disease. Conditional on the presence of a given pathogen, its actual spread is likely to be negatively related to the level of development and health infrastructure of each country. Also, despite the fact that less developed countries have the highest recorded number

\footnotetext{
${ }^{27}$ Malaria is a very special case in this context, as it is the only disease one that is sometimes alternatively classified as human only, rather than multi-host, since the only non-human reservoir is the vector itself. This specific feature makes malaria easier to treat and eradicate than, e.g. dengue, despite the fact that no effective vaccine is available yet. For these reasons we do not include malaria in the Disease Richness (Deadly) index to be conservative. The results are unaffected by the inclusion of malaria, because it does not fundamentally change the informational content of the indexes.

${ }^{28}$ This coding helps correcting the bias for these diseases since, for instance, using this criterium several OECD countries like Belgium, Canada, Denmark, France, Germany, and Italy are coded as Malaria countries although the diseases has been officially eradicated in these countries as since at least the 1960s.
} 
of human pathogens, the information for a particular pathogen ever having been observed is fairly reliable. Even if these countries have less reliable statistical records, MHV diseases are typically carefully monitored by international agencies. Potentially incomplete information about particular diseases is likely to be random, which implies that these indexes of disease richness constitute a conservative measure which is likely to underestimate the actual burden of exposure to diseases in underdeveloped countries compared to more developed ones.29 Differently from health outcomes, the disease richness indices take discrete values. These features limit the informational content of these measures compared to continuous and time-varying measures of outcomes like life expectancy or death rates. Nevertheless, in the context of predicting civil conflict, these measures have important advantages. First, due to the specific features of MHV pathogens, the measures are credibly unaffected by the incidence and intensity of a conflict in a given country in a given period of time. This further limits the potential for problems of reverse causality. Second, while measurement error is a serious problem when dealing with health outcomes, the verification of the existence of each one of these important diseases in a country is substantially more reliable, even in developing countries.

Data on Civil Conflicts. The main data source for civil wars and conflicts is the UCDP/PRIO Armed Conclict Dataset (version 4/2009) provided by the Peace Research Institute of Oslo (PRIO) ${ }^{30}$ The main dependent variable, denoted "Civil War (PRIO)" indicates conflicts with at least 25 battlerelated deaths per year and more than 1000 battle-related deaths over the entire duration of the conflict. The sample used in the regression includes up to around 140 countries over the period 1960-2004. In the benchmark specification we consider the probability of observing the incidence of a conflict in five-year intervals, which gives around 900 observations with information on conflicts as well as all other control variables, and around 4600 observations when considering the probability of conflict at the yearly level. The incidence of conflicts of lower intensity is investigated using the "Civil Conflicts (PRIO)" variable, which reflects internal and internationalized internal conflicts (types 3 and 4 of the PRIO definition) and includes all conflicts involving more than 25 battle related death

\footnotetext{
${ }^{29}$ In the context of classical measurement error this means that the coefficients on disease richness reflect a lower bound of the true effect.

${ }^{30}$ In particular, we use the UCDP/PRIO Armed Conflict Dataset v.4-2010, 1946 2009, based on Gleditsch et al. (2002) and updated by Harbom and Wallensteen (2010), and restricted to the period 1960-2005 for consistency. See http://www.pcr.uu.se/research/UCDP/data_and_publications/datasets.htm for a data description. We focus on the incidence of internal armed conflicts in each country, which are defined as a "contested incompatibility concerning government and/or territory where the use of armed force between two parties, of which at least one is the government of a state".
} 
per year (and not necessarily more than 1000 deaths in total). For robustness, we also use the data on intra-state war data provided by Correlates of War Dataset ("Conflict (COW)"), the data used by Doyle and Sambanis (2000) ("Conflict (DS)"), and the data of Fearon and Laitin (2003) ("Conflict $(\mathrm{FL}) "){ }^{31}$

Data on Economic, Institutional and Geo-Climatological Co-variates. In the baseline specification we control for the main determinants and covariates of conflict that have been identified in the literature ${ }^{32}$ Population pressure is accounted for by including log population density, or log population and log country size separately, as explanatory variables ${ }^{33}$ Controlling for population accounts for the possibility that a large population implies difficulties for central authorities in observing developments at the local level, and increases the number of potential rebels that can be recruited by the insurgents, see, e.g., Fearon and Laitin (2003), and is important in the context of scale effects 44 Additional determinants of conflict that have been emphasized in the literature include: an index of ethno-linguistic fractionalization and, more importantly, ethnic polarization (Montalvo and Reynal-Quérol, 2005a, 2005b) and alternative measures of religious fractionalization and polarization; log GDP per capita as a measure of economic living standards 35 and the proportion of GDP made up by primary commodity exports ${ }^{36}$ To reflect political variables that might influence the propensity of civil war, we include an indicator variable for democracy ${ }^{37}$ As controls for the

\footnotetext{
${ }^{31}$ In the COW dataset, "intrastate wars are wars that are fought within state borders between a government and non-government forces (civil war), or at least two non-government forces (inter-communal war)" with at least 1000 cumulative deaths and without reference to a minimum number of deaths per year.

${ }^{32}$ In particular, we refer to Fearon and Laitin (2003), Doyle and Sambanis (2000), Collier and Hoeffler (1998, 2002, 2004), and Montalvo and Reynal-Querol (2005b) (see also Blattman and Miguel, 2010, for an extensive survey).

${ }^{33}$ In principle, population density and population size may have different effects on conflict. We therefore report the results for both specifications.

${ }^{34}$ Collier and Hoeffler (2002) find that the elasticity of civil conflict risk with respect to population is generally less than one, indicating that large countries are relatively safer. In a causal setting for African countries, Brückner (2010) finds that faster population growth increases the risk of conflict.

${ }^{35}$ Fearon and Laitin (2003) identify income per capita as a proxy for a "state's overall financial, administrative, police and military capabilities". Higher per capita income should thus be associated with a lower risk of civil war. Collier and Hoeffler (1998) point that low income per capita implies a lower opportunity cost of engaging in civil war and lower costs associated with the disruption caused by warfare.

${ }^{36}$ Primary commodity exports serve as a measure of the natural resource endowment, which can be diverted by rebelion and thus constitute a key element for financing a civil war, see Sachs and Warner (1995) and Collier and Hoeffler (2002).

${ }^{37}$ The indicator is based on the index constructed by the Polity IV project which measures political freedom, and hence the quality of democratic institutions, on a scale from 0 to 10, with higher values reflecting better democracies.
} 
physical characteristics of countries, we include measures for the percentage of mountainous terrain in a country and a dummy for whether the land mass of a state is contiguous 38

To account for geographical characteristics, we add further controls to the baseline specification: absolute latitude, the logarithm of the distance from the centroid of a country to nearest coast (in $\mathrm{km}$ ) and the share of the total population within a $100 \mathrm{~km}$ distance of ice-free coast ${ }^{39}$ In the tables below these controls are summarized under the heading of "Geographical Controls".

The main variables of interest, most notably the extrinsic disease environment, but also ethnic polarization and other geo-climatological country specificities, are time invariant. This precludes the possibility of estimating their impact while including country fixed effects. To account for unobserved heterogeneity in regions, the analysis makes use of regional dummies, which allows to exploit the within region variation for relatively small groups of countries. We include regional dummies for small regions which include about twelve countries on average.40 The baseline analysis therefore exploits within region variability. Finally, we include a set of common period effects for each five-year interval to account for possible trends and waves in conflict incidence in particular periods. This accounts for the increasing number of civil conflicts after the end of the cold war, where the maximum number of conflicts has been observed in the 1990's4

In addition, the analysis applies an extensive set of controls in further robustness checks: religious polarization (data from Montalvo and Reynal, 2005b), Social Fractionalization (data from Collier and Hoeffler, 2004), Ethno-linguistic Fractionalization (data from Desmet, et al., 2009), life expectancy at birth (UN World Population Prospects, 2006), the proportion of fuel exports in GDP (taken from Fearon, 2005), constraints on the executive (from the Polity IV Dataset), average years of schooling in the male population (Barro and Lee, 2001), income inequality (Gini Index from the WIID dataset), colonial origins (data from the ICOW Colonial History Dataset) and the index of We follow Montalvo and Reynal-Querol (2005b) and transform the index into a binary variable for democracy, taking value 1 if the index is higher or equal to 4 .

${ }^{38}$ Mountainous terrain can provide suitable hiding places for rebels. The second variable refers to countries with a territory that holds at least 10.000 people and that is separated from the land area containing the capital city either by land or by $100 \mathrm{~km}$ of water. This variable reflects the possibility that the incidence and the spread of civil wars might be affected by long distances from the capital of the state.

${ }^{39}$ These data are taken from the Physical Geography and Population data set (revised data 9/04/01), provided by the Center for International Development at Harvard University.

${ }^{40}$ These regions classify countries in Asia, Asia Pacific, Sub-Saharan Africa, North Africa, Middle East, Central America, South-America and Europe.

${ }^{41}$ The proportion of countries with conflicts increases from about 10 percent in the 1960 s to above 20 percent in the 1990s see, e.g., Collier and Hoffler (2004) and Blattman and Miguel (2010). 
settler mortality from Acemoglu, Johnson and Robinson (2001). Following the literature on disease ecology, we also use data on the average temperature in each country, which has been documented to be a key determinant of the disease richness across countries ${ }^{42}$

In a final step, we follow the literature in development economics and epidemiology and investigate the effect of climatological shocks (or natural disasters), as well as their interaction with the disease environment, on the incidence of conflict. This analysis uses yearly data on the occurrence and number of droughts in each country and year for the period 1960-2005.43 A further advantage of using exogenous variation in climatological shocks and the interaction with disease environment is that it allows us to investigate the role of (time-invariant) disease environment while accounting for time invariant unobserved heterogeneity across countries by controlling for country fixed effects.

\section{Results}

\subsection{Preliminary Analysis.}

Table 3 reports the descriptive statistics of the data. On average, the incidence of Civil War (PRIO classification) was about 0.16 over all five-year periods from 1960-2004 in all countries in the data set. The incidence of the lower intensity, Civil Conflict (PRIO), was 0.25. The incidence of civil conflict in terms of the Civil War (PRIO) classification in the observation period across the world is displayed in Figure 1(a). The alternative conflict measures that are used as dependent variables in the analysis are summarized in Table 4.

A first indication for the potential role of the disease environment for civil conflict emerges from the summary statistics in Table 3. The worldwide distribution of MHV diseases is illustrated in Figure 1(b). The average Disease Richness (Deadly) is around 2.9 pathogens. When splitting the sample into countries that experienced no civil wars and countries with at least one such conflict, the measure of disease richness displays a pronounced difference of $2.45 \mathrm{MHV}$ deadly diseases in countries with no conflict, but 3.66 MHV deadly diseases in countries with conflicts. This difference appears to be more pronounced than the difference in any of the other main control variables. Similar comments apply to the Disease Richness (Endemic) variable with a mean of 2.84 diseases,

\footnotetext{
${ }^{42}$ See Guernier et al. (2004) for the ecological analysis of the geographical and climatological determinants of the spatial distribution of human diseases. The data on temperature are taken from the HCN-Monthly data from the NOAA Satellite and Information Service available at http://www.ncdc.noaa.gov/oa/climate/ghcn-monthly/index.php.

${ }^{43}$ The source of the information on disasters is EM-DAT: The OFDA/CRED International Disaster Database, see http://www. emdat. be, Universit Catholique de Louvain, Belgium. We use the version of November 2009.
} 
but a difference between countries without and with conflict that is even slightly more pronounced (2.36 versus 3.66). The Disease Richness (MHV) index also differs substantially. Apart from that, countries experiencing civil wars also seem to have lower income, less likely to be democracies, and to have higher ethno-linguistic polarization. In terms of exogenous geo-climatological conditions, countries that had civil wars have more mountainous terrain, are more exposed to the likelihood of climatological shocks in terms of droughts, and have higher average temperatures.

A similar picture emerges from the correlations of the variables of main interest, displayed in Table 5. The correlation between the three measures of disease richness is fairly high (with a correlation coefficient of around or above 0.9), indicating that the three measures nevertheless capture slightly different information on the disease environment. The disease environment is highly correlated with exogenous geo-climatological characteristics that appear to favor the presence of the respective pathogens. These include in particular average temperature and absolute latitude. This pattern is also illustrated by Figure 2, which visualizes the correlations between geographic environment, disease richness and civil conflicts graphically by means of scatter plots. Figure 2(a) displays the correlation between absolute latitude and the benchmark measure of disease richness (Disease Richness, Deadly), while Figure 2(b) depicts the respective correlation with average temperature in the period 19501960. These plots illustrate the findings by Smith et al. (2007) that the country specific climatological conditions, which are essentially related to geographical characteristics, are strong determinants of the exposure to human pathogens for the class of MHV diseases. Finally, Figure 2(c) illustrates the positive correlation between the number of deadly MHV diseases and the number of five-year intervals with at least one conflict in the period 1960-2004.

\subsection{Disease Environment and Incidence of Civil Conflicts}

Baseline Results. Given the binary coding of the dependent variable, we estimate Probit models as benchmark specification and report the marginal effects computed at the respective means. Standard errors are robust and allow for clustering at the country level. For direct comparability of the quantitative effects across different explanatory variables, all explanatory variables are standardized on the respective estimation sample, with the exception of region and period fixed effects and the binary indicators ${ }^{44}$ The time-varying explanatory variables are measured at the beginning of the respective five year periods over which the dependent variable is measured.

\footnotetext{
44 The binary indicators for non-contingent land mass has mean 0.17 and standard deviation 0.37 while democracy has mean 0.49 and standard deviation 0.50 in the baseline sample.
} 
Table 6 presents the main results of the determinants for the incidence of social conflict. As a benchmark, Columns (1) and (8) replicate the standard specification in the literature, suggesting that higher population density, a higher degree of ethnic polarization, and lower income per capita increase the likelihood of observing a civil war 45 The central finding is the strong positive effect of disease richness on the incidence of civil wars, which is documented in the other columns of the table. The effect is robust across the different specifications, in particular with respect to adding geographical controls, controls for regions, and fixed effects for five-year periods, as well as to using population and country size as separate controls 46 The inclusion of regional dummies implies that the analysis exploits variation within regions, thereby allowing for regional specific effects. The effect of the benchmark measure of Disease Richness (Deadly) is quantitatively important, given that the estimates imply an increase of 5.7-7.5 percentage points in the likelihood of conflict for a onestandard deviation increase in disease richness. In light of an unconditional probability of conflict of 16.2 percent, this corresponds to an increase in the likelihood of conflict incidence of 35-46 percent 47 The results for the other controls are similar to the findings in the previous literature, although the inclusion of disease richness tends to reduce their statistical significance. In particular, a higher degree of ethnic polarization significantly increases the probability of a conflict. Richer countries, in terms of higher GDP per capita, as well as democracies experience less conflicts, even though these results are not statistically significant once the disease environment is controlled for. Countries with a geographical terrain that facilitates insurgencies, reflected by the measures of non-contingent land mass and mountainous terrain, exhibit higher probabilities of civil conflict, albeit the latter effect is generally insignificant.

The main result from these estimates is that disease richness appears to be among the most important determinants of civil conflict in terms of statistical significance and explanatory power. This is also documented by the explanatory power that is added by this variable compared to the

\footnotetext{
${ }^{45}$ This benchmark specification essentially follows Fearon and Laitin (2003) and Montalvo and Reynal-Querol (2005b), which we extend by considering the geographical controls discussed in the previous section, as well as regional dummies and period dummies. Using logit models and restricting to the shorter observation period investigated by Montalvo and Reynal-Querol (2005b), delivers qualitatively identical results. The main difference is that restricting to the shorter period the effect of the non contingent land dummies tends to be less significant. Detailed results are available upon request.

${ }^{46}$ The results for disease richness are qualitatively unchanged and quantitatively slightly larger when using more flexible functional forms for country size, e.g., by adding squared and cubed terms. Detailed results are available upon request.

${ }^{47}$ In the estimations, the measure of Disease Richness (Deadly) is standardized, as described above. The original variable is measured on a support from 0 to 6 with mean 2.90 (standard deviation 1.56).
} 
most important determinants highlighted in the previous literature. In a parsimonious specification without disease richness and ethnic polarization, and without geographical, regional and period controls, the Pseudo-R-squared (log Likelihood) is 0.07 (-371). When adding ethnic polarization as explanatory variable, the Pseudo-R-squared (log Likelihood) increases to 0.107 (-357). When adding the index of Disease Richness (Deadly) as an explanatory instead of ethnic polarization, the respective statistics are 0.123 (-351), whereas when adding both the statistics are $0.143(-343)$ as in the specification of column (2) of Table 6$]^{48}$ Hence, the disease environment appears to contribute as much or more explanatory power as does ethnic polarization, which is one of the most robust time-invariant explanatory variables in the previous literature as well as in the baseline specification together with the disease environment. These main results are confirmed by the extensive robustness checks reported below.

Alternative Measures of Disease Richness. Table 6 also presents the estimation results for the alternative measures disease richness: the index of disease richness in terms of endemic MHV diseases with a high fatality risk, Disease Richness (Endemic), and the broader measure of disease richness in terms of all multi-host vector transmitted diseases that have ever been detected in a country regardless of their fatality, Disease Richness (MHV). These results confirm that the disease environment has a strong positive effect on the risk of civil wars. This finding emerges out of all specifications, irrespective the actual coding. The role of disease richness is quantitatively very similar to the results obtained with the baseline specification for the deadly diseases, but is slightly lower and less significant when measuring the exposure to all MHV diseases. The results overall suggest that the information on the measures of disease richness, which essentially summarizes the worldwide distribution of this class of diseases, is informative about the relevant cross-country differences in the incidence of civil war, irrespective of the actual coding of the measures in terms of particular diseases composing the indexes $\sqrt[49]{ }$ It is worth noting, however, that the point estimates are about 20 percent lower for the broader category of disease richness (MHV) compared to the measure of richness of deadly diseases, which could indicate that the broader index underestimates the relevant opportunity costs for conflict.

\footnotetext{
${ }^{48}$ For the model with geographical, regional and period controls, but without ethnic polarization and disease richness, Pseudo-R-squared (log Likelihood) are 0.207 (-317). Adding ethnic polarization implies statistics of 0.227 (-309), while adding Disease Richness (Deadly) results in 0.250 (-298). The statistics for the full specification displayed in column (3) of Table 6 are $0.272(-291)$.

${ }^{49}$ This is further confirmed by sensitivity analysis with respect to eliminating particular diseases from the index presented in Table 10 and discussed below.
} 
Different Sub-Samples: Non-OECD Countries and African Countries. A potential confound of the results presented before could be that disease richness is a significant predictor of the risk of civil wars due to differences in overall levels of development. Disease richness would then essentially reflect the differences between rich and poor countries. In order to investigate whether the role the disease environment has an independent effect from economic development level in more detail, we present estimated the effect for the sub-samples of less developed countries that are not member of the OECD, as well as for the sub-sample of African countries 50 This implies restricting the analysis to variation within the set of the less developed countries compared to the baseline results.

The estimation results are reported in Table 7. They essentially confirm the baseline findings and document that the role of the disease environment is not driven by the markedly different unconditional risk of civil wars between the more and less developed countries. The effect of the disease environment is even larger when restricting attention to Non-OECD countries. The estimates imply an increase of 10.6-12.8 percentage points in the likelihood of conflict incidence for a onestandard deviation increase in disease richness which compared to an unconditional probability of conflict of 20.1 percent implies an increase of 58-64 percent. The effect of disease richness also emerges for the sample of African countries. The estimates imply an increase of 5.8-8.4 percent that compared to an unconditional probability of conflict of 13 percent implies an increase of 4464 percent. In fact, within Africa, differences in disease environment is one of the few significant variables that is left after including geographical and period controls. It is worth noting that the point estimates obtained with the sample of African countries are virtually identical to those obtained with the baseline sample, despite the substantially smaller sample size. ${ }^{51}$ Compared to the baseline results obtained with the sample of all countries, the empirical model also exhibits a better fit when estimated on the sub-samples of Non-OECD countries or African countries. Thus, the results for the sub-samples of non-OECD countries and African countries document that the effect of disease richness on the likelihood of civil conflict is very homogenous across samples of countries with very different levels of economic development.

\footnotetext{
${ }^{50}$ The sample of Non-OECD countries essentially coincides with the sample of former colonies (broadly defined), with only few exceptions like for instance Saudi Arabia, or China which were not colonies and US and Canada that are OECD countries but were colonies. For that sample the mean disease richness is 3.34 with standard deviation 1.34 while for African countries the respective values are mean 3.72 and standard deviation 1.28.

${ }^{51}$ Besides the role of diseases, another determinant of civil war that sticks out in these estimates is whether a country is a primary exporter, which is more significant than in the sample with all countries. This could reflect a higher stability of regimes with strong economic interests and capabilities to ensure that stability.
} 


\subsection{Robustness}

This section continues by presenting the results of several additional estimations in order to investigate the robustness of the previous findings. These robustness checks include the consideration of alternative measures of conflicts, alternative econometric specifications, alternative data frequencies, and a sensitivity analysis of the results with respect to each of the different MHV diseases. Finally, the analysis includes a set of additional controls that have been applied in the literature and further geographical controls (both in the full sample and in the sub-samples) in light of the close link between disease environment and local country specific geo-climatological conditions.

Alternative Measures of Civil Conflicts. The finding of a significant effect of disease richness on the incidence of conflict is robust with respect to the use of alternative measures of conflicts. Table 8 presents results for several alternative definitions of civil conflict that have been used in the empirical literature: a measure that also includes conflicts with lower intensity than those captured by the measure Civil War (PRIO), denoted by Civil Conflict (PRIO); a measure of conflict from the the correlates of war (COW) data set; and measures of conflict constructed and used by Fearon and Laitin (2003) (FL) and Doyle and Sambanis (2000) (DS) 52 The results presented in Table 8 document a strong and consistently positive effect of the different measures of disease richness on the propensity of civil conflict, regardless of the particular definition or measure of conflict. For the Conflict (PRIO) measure of intermediate intensity conflicts, an increase of one standard deviation in disease richness increases the unconditional probability of conflict by 30-40 percent. Despite the lower unconditional probability of conflicts events in the other conflict definitions, the effect is positive and significant, but quantitatively smaller. The index of Disease Richness (Deadly) that only includes fatal MHV diseases by and large exhibits the statistically and quantitatively strongest results. Another noteworthy finding is that the coefficient of the disease richness index as well as its statistical significance is roughly comparable across the different definitions of conflicts, whereas this is generally not the case for other standard determinants of conflict. These conflict determinants display a significant effect for some conflict definitions, but not for others. As in the baseline results for Civil Wars (PRIO) as dependent variable, the effect of the disease environment is similar or even slightly stronger when restricting the sample to Non-OECD countries or African countries, and using

\footnotetext{
${ }^{52}$ Data for the conflict variables by Fearon and Laitin (2003) and Doyle and Sambanis (2000) are taken from the data set provided by Montalvo and Reynal-Querol (2005b).
} 
the the alternative definitions of conflicts 53

Alternative Data Frequencies and Estimation Methods. The analysis so far has followed the literature in estimating the determinants of the incidence of conflict based on a cross-country panel with five-year periods. This has the advantage of limiting potential reverse causality by using predetermined explanatory variables, while retaining time-varying information in the dependent variable and in some of the explanatory variables ${ }^{54}$

Due to the fact that the disease richness is time-invariant, the estimation cannot account for time-invariant unobserved heterogeneity across countries by including country fixed effects, however. In order to investigate the robustness of the results, we estimated the model using a random effects specification to account for unobserved heterogeneity, The results from these estimations are presented in columns (1)-(4) of Table 9 and essentially confirm the baseline results 55

As an alternative robustness check, we also estimated cross-sectional models. Given that the main identifying variation from the disease richness measures is across countries, this is informative as these estimation results do not rely on any time-varying information in the dependent variable or in any of the other explanatory variables. Columns (5) to (8) of Table 9 contain the respective results from Tobit models, where the dependent variable is the number of five-year periods over the horizon 1960-2004 with an incidence of a civil conflict in a particular country. There is censoring at zero for those countries that had no civil conflict over the entire observation period. All timevarying explanatory variables are measured in 1960. Again, the results are qualitatively identical to the baseline results: higher disease richness implies a higher number of five-year periods with an incidence of civil conflict. Also the results for ethnic polarization and for population density are similar to the results obtained with the baseline specification.

As a final robustness check with respect to the data frequency, we estimated the model using yearly data, rather than data in five-year intervals. The respective results are presented in Columns (9)-(12) of Table 9. The findings confirm that a larger exposure to diseases in terms of the disease richness measures has a large and statistically robust positive effect on the risk of a civil war ${ }^{56}$

\footnotetext{
${ }^{53}$ The respective results are reported in the Tables 14 and 15 that are included as additional material non intended for publication.

54 The results on the effect of disease richness on conflict incidence are similar when potentially endogenous variables like income per capita or democracy are excluded from the specification.

${ }^{55}$ The table presents coefficient estimates, which are not directly comparable to the marginal effects reported in the earlier tables. Nevertheless, the effects are quantitatively comparable to the respective coefficient estimates that correspond to the Probit estimates presented before. Details are available upon request.

${ }^{56} \mathrm{An}$ increase in disease richness of one standard deviation more than doubles the unconditional probability of civil
} 
Robustness to the Exclusion of Single Diseases. To investigate whether some of the diseases are more relevant than others in increasing the incidence of civil wars, we performed an additional sensitivity check by creating alternative disease richness indices that exclude each of the diseases, one by one at a time. The corresponding results are reported in Table 10 . They show that the earlier findings on the effect of disease richness on civil conflict are not driven by the the inclusion of any particular disease. Rather, the results suggest that it is the aggregate level of disease richness that matters for the incidence of civil conflict. The unreported results of the same sensitivity analysis of eliminating single diseases from the alternative measures of disease richness deliver similar findings. In line with the arguments presented in the previous section, this suggests that the index of disease richness refers to a broad measure of cross-country differences in the exposure to infectious disease pathogens, rather than reflecting the effect of a particular disease.

Additional Controls. As a final robustness check, we estimated specifications with additional controls that have been proposed in the literature as potential determinants of civil conflicts. These controls can be organized in three categories. The first category includes alternative measures of social tensions, in terms of religious, ethnic, and social polarization or fractionalization. The second category includes additional geo-climatological characteristics, like average temperature and the number of droughts, as well as other variables that are related to the geographic environment, like the share of GDP accounted for by fuel exports, and life expectancy at birth (at the beginning of the observation period in 1955-1960 or at the beginning of each five-year period) 57 We also conducted additional unreported estimates with alternative control variables for climate, including KöppenGeiger climate zones, precipitation, or variation in temperature. The inclusion of these variables wars, which is about 0.03 in the data with yearly frequency. All time varying variables are lagged by one year. Using higher lags does not change the results.

${ }^{57}$ Notice that, as discussed above, life expectancy at birth does not represent an alternative measure of disease richness, but rather reflects a control variable. Differently from the index of disease richness, which is conceptually unaffected by development and (localized) civil conflicts by construction, life expectancy at birth is likely to be affected by the level income and endogenous with respect to violent conflicts. To limit this problem, we include life expectancy in 1950-1960 but the correlation between life expectancy (1950-1960) and income per capita (measured over the full period) remains as high as 0.80 , while the correlation between the measure of disease richness and income per capita is -0.55. An additional caveat regarding the inclusion and interpretation of life expectancy as a control is that life expectancy is likely to be affected by substantial measurement errors (particularly in the poorest countries), and mainly reflects differences in infant mortality across countries, rather differences in than adult mortality and general health conditions, see, e.g., Bleakley (2007), Lorentzen, McMillan and Wacziarg (2008), Jayachandran and Lleras-Muney (2009), among others. 
involve further reductions in sample size, but the results are similar to those presented below. These results are available upon request. The third category of additional controls includes further economic and institutional variables in terms of the average years of schooling in the male population, income inequality, colonial origin, institutional quality in terms of constraints on the executive, and settler mortality, which has been used frequently in the literature as instrument for institutional quality ${ }^{58}$

The estimation results for the specifications including each of these controls are shown in Columns (1)-(13) of Table 11. Due to data availability, the inclusion of some of these controls (in particular of education, inequality and institutions) leads to a substantial reduction in the number of observations that can be used for estimation. This potential sample selection issue needs to be kept in mind when interpreting the results. Columns (14)-(16) report the results when including all additional controls of the three categories of demo-social, geographic and economic-institutional variables, respectively.

Overall, the results document that the effect of disease richness on conflict incidence is robust to the inclusion of the additional controls. It is remarkable that, despite the sizable reduction in the number of observation in some of the specifications, the results confirm the quantitatively important and statistically robust role of disease richness. In line with previous findings in the literature, some of the additional control variables are also significantly related to civil conflicts, such as the index of ethno-linguistic fractionalization proposed by Desmet et al. (2009), the share of fuel export over GDP proposed by Fearon (2005), the colonial origin, and index of settler mortality proposed by Acemoglu, Johnson and Robinson (2001) all matter for predicting the incidence of civil wars, in addition to the other controls in the baseline specification 59 The results are very similar when restricting the sample to Non-OECD countries or African countries 60

\footnotetext{
${ }^{58}$ The settler mortality index measures mortality of groups of European settlers in the colonies between the seventeenth and nineteenth centuries, and goes back to work of the historian Philip D. Curtin, see Acemoglu et al. (2001) for a detailed description. Similar to life expectancy, the settler mortality index should be seen as additional control to test the robustness of the results, rather than as an alternative measure of disease environment, because it reflects mortality of European settlers, and not the overall disease environment in terms of the number of diseases detected or endemic in a country.

${ }^{59}$ Compared to countries that were never colonized (which is the omitted reference category), French and UK colonies are less likely to have civil wars, there is no effect on colonies of other powers (Spanish and Portuguese colonies).

${ }^{60}$ The results are reported in Tables 16 and 17 in the additional material.
} 


\subsection{Disease Environment and Climatological Shocks}

Finally, we turn to the investigation of the effect of interactions between the disease environment and the occurrence of climatological shocks in terms of droughts on the incidence of civil conflict. The consideration of interactions between the time-invariant measures of disease richness and the timevarying occurrence of droughts allows for exploiting within-country variation over time, and thus for the inclusion of country fixed effects to account for time-invariant unobserved heterogeneity across countries. In this specification, the main effects of the time-invariant measures of disease richness are not identified, but the interaction terms with the time varying variables can still be estimated.

The International Disasters Database codes a drought as an "extended period of time characterized by a deficiency in a region's water supply that is the result of constantly below-average precipitation." In the estimation sample, there are about 2000 episodes of droughts over the 44-year horizon, with an average duration of two and a half months and a standard deviation of 7 months. About 85 percent of droughts last around one month, 10 percent last more than one and less than six months, and a minority (less than 5 percent) last more than a year and up to 5 years in few countries. To exploit the annual data on climatological shocks in terms of droughts, we consider the annual sample as benchmark for this analysis.

Table 12 presents the results for the incidence of conflict in terms of the measure Civil War (PRIO) obtained from a logit specification with country and year fixed effects in columns (1)-(6), and a probit specification with random effects in columns (7)-(12). Column (1) reports the results from a specification with all the time-varying controls from the baseline specification, including $\log$ population density, log income per capita, primary exports and the indicator for democracy, together with a measure of the number of droughts in the previous year in each country, as well as year fixed effects and country fixed effects.61 Since the disease richness indicators are time-invariant, they are not identified in this specification. The only significant determinant of civil conflict in this specification is income per capita. ${ }^{62}$ In column (1), the measure "Droughts", which reflects the number of droughts in a country in the past year, does not appear to significantly increase the risk of civil wars 63

Columns (2), (3), and (4) present the results for the same specification, but including an interaction between the disease environment (measured using the different indices of Disease Richness)

\footnotetext{
${ }^{61}$ The results are similar or slightly stronger when restricting to the occurrence of droughts in the present year, rather than in the previous year.

${ }^{62}$ This result is in line with the findings by Miguel et al. (2004).

${ }^{63}$ Only 5 percent of all country-years with droughts correspond to several droughts in a single year.
} 
and the occurrence of a drought in the previous period. The results document the existence of a significant and positive interaction between droughts and the disease environment. This suggests that climatological shocks such as droughts increase the incidence of civil war particularly in countries with a high disease exposure in terms of the different measures of disease richness. To investigate the robustness of these findings with respect to the coding of droughts and diseases, we created a binary measure indicating "high disease exposure" countries (denoted by variable "HD" in the tables) that takes value 1 if a country has a number of diseases which is above the average in the sample, and 0 otherwise ${ }^{64}$ Column (5) presents the results for a specification that includes the interaction between the high disease dummy, HD, and the number of droughts. Column (6) includes an interaction between the HD dummy and a binary drought indicator that takes value 1 if a country experiences at least one drought in the previous period, and 0 otherwise. The results confirm the existence of a significant positive interaction between the disease richness and the occurrence of droughts in explaining civil war incidence. Another interesting finding concerns the main effect of droughts in the specifications with a binary indicator of disease richness, which suggests that the number or incidence of droughts reduces the risk of a civil war in countries with below average disease richness (compared to periods without droughts), but increases the risk of civil war in countries with above average disease richness.

Columns (7) to (12) of Table 12 report the results for a random effects probit model, rather than a fixed effects logit estimation. In the random effects specification, the main effect of disease richness is identified. Consistent with the previous findings, a higher disease richness is associated with a higher incidence of civil war. In addition, and similar to the results in columns (1)-(6), we find a significant positive interaction effect indicating that droughts have a stronger effect on the incidence of conflict in countries with a high disease richness. The random effects are also useful for gauging the quantitative importance of the effects. The results in column (7) are similar to the random effects estimates obtained with the 5-year frequency data in Table 9. In comparison to that, the results for the main effects are very similar in the specification with interactions, whereas the interaction effect is about 20 percent of the main effect. In light of the substantial quantitative size of the effects of disease richness on conflict described before, this implies that climatological shocks provide a considerable source of additional variation in explaining civil conflicts in counties with a high disease burden.

Table 13 reports the respective results for the measure Civil Conflict (PRIO) that also includes

\footnotetext{
${ }^{64}$ Given the high correlation between the different indexes the high disease indicator is the same regardless of the actual index used for its generation.
} 
civil conflicts with lower intensity than the civil war measure. The results are qualitatively similar. Quantitatively, the interaction effect between droughts and disease richness is about half the size as in the estimates with civil incidence war as dependent variable. Even though climatological shocks in terms of droughts appear to have a smaller effect on the intensity of conflicts with a lower intensity, they exert a significant effect in interaction with the disease environment (or only in high diseases countries). Qualitatively identical results are obtained when replicating the analysis in a panel data set with five-years frequency, when using the definition of conflict from the Correlates of War (COW) data set, or when considering heat waves in addition to periods of droughts. ${ }^{65}$ The results are robust and even stronger when considering contemporaneous droughts, rather than droughts in the past year ${ }^{66}$ Overall, the results confirm the finding that high disease richness increases the likelihood of civil conflict or civil war incidence, but this effect is magnified by the occurrence of climatological shocks like droughts.

\section{Concluding Remarks}

This paper has investigated the hypothesis that countries with a high and persistent exposure to potentially deadly infectious diseases face a higher risk of violent civil conflicts. The disease environment is measured by using newly available data on the worldwide distribution of human pathogens in the class of multi-host vector-transmitted infectious diseases. The new measure of disease richness builds on recent findings in ecology and micro-biology that document that the cross-country differences in the exposure to multi-host vector-transmitted human diseases are primarily determined by country specific geo-climatological conditions that enable the existence and reproduction of the pathogens and their transmission vectors. As consequence of the fact that they reproduce in multiple hosts, disease agents of this class are very resistant to eradication campaigns. Since they are transmitted through vectors, which require a particular geo-climatological habitat, these diseases are endemic only in particular areas and thus very localized. Finally, diseases of this type have substantial direct and indirect relevance for general health conditions and mortality. These characteristics imply that cross-country differences in the number of these diseases in each country provide an informative measure about the differences in the extrinsic disease environment (in terms of disease richness) that

\footnotetext{
${ }^{65}$ The corresponding results are reported in the additional material not intended for publication in Tables 18 and 19, respectively. The results for the COW data should be taken as suggestive, given the very low unconditional probability of conflicts (1 percent) at the yearly level in that data set. The inclusion of heat waves tends to increase the significance of the results.

${ }^{66}$ Results are available upon request.
} 
can be considered exogenous for the purpose of this study of (localized) civil conflicts.

The results document that the risk of civil conflicts is consistently and significantly higher in countries that are exposed to harsher disease environments in terms of a higher disease richness, thereby complementing the existing literature on the demo-economic, social and institutional determinants of civil conflicts. The findings are robust to extensive robustness checks, including different measures of disease richness and civil conflicts, the use of different data frequencies, the inclusion of a rich sets of additional controls, and alternative estimation techniques. Similar findings consistently emerge also when restricting the sample to developing countries or African countries. The analysis also documents significant interactions between the occurrence of climatological shocks in terms of droughts and the disease environment for the incidence of civil conflict, even when using variation within countries overtime.

Overall, the evidence presented in this paper suggests a potentially very relevant role of the disease environment for civil conflicts and, indirectly, for economic development, which has not been investigated in the existing literature. The findings are particularly noteworthy in view of the fact that the measures of disease richness have been obtained from the mere counting of the number of multi-host vector-transmitted diseases that have ever been detected in a country, or are currently endemic in a country. This represents a conservative way to measure of the cross-country differences in the exposure to infectious diseases and their prevalence in the population, which appears unlikely to be affected by problems of measurement error or endogeneity.

By highlighting the link between disease richness and civil conflict, the findings provide another perspective of the recent warnings in the medical literature and by international organizations, like the WHO, about the role of the disease environment for human health and, specifically, the need for a more intensive fight of vector-transmitted diseases. In light of the interaction between disease environment and droughts in explaining conflict incidence, the results also provide another aspect to the potential consequences of global warming and the related increase in the prevalence of droughts and in the spread of climatological conditions that favor the vectors that transmit infectious diseases. It is nevertheless important to stress that the empirical analysis performed in the paper does not allow for (and is not designed for the purpose of) deriving more specific policy prescriptions beyond providing evidence for a new, but potentially very relevant, rationale for fighting vector-transmitted diseases as well as establishing good general health conditions. As discussed in the Introduction, the literature has pointed out several, non-mutually exclusive, reasons why a poor health environment may increase the risk of violent conflicts. More detailed policy implications would require the identification of the main channels behind the empirical results. This appears far from an easy task, 
however. In fact, even the exact channels through which the more intensively investigated and better documented determinants of civil conflict, like adverse income shocks or deficient institutions, lead to increased conflict incidence are not fully understood.

The main and, we believe, most relevant contribution of this paper is a first step towards a systematic empirical investigation of the role of the disease environment for civil conflicts, an issue that has not been explored in the existing literature on the determinants of civil conflicts. The finding that harsher disease environment is related to the incidence of civil conflict and interacts with relevant short term phenomena like climatological shocks suggests interesting directions for future research. 


\section{References}

Acemoglu, D., S. Johnson, and J. A. Robinson (2001): "The Colonial Origins of Comparative Development: An Empirical Investigation," American Economic Review, 91(5), 1369-1401.

Barro, R. J., And J. LEe (2001): "International Data on Educational Attainment: Updates and Implications," Oxford Economic Papers, 53(3), 541-563.

Becker, G. S., T. J. Philipson, and R. R. Soares (2005): "The Quantity and Quality of Life and the Evolution of World Inequality," American Economic Review, 95(1), 277-291.

Besley, T., and T. Persson (2009): "Repression or Civil War?," American Economic Review, 99(4), 292-297.

(2011): "The Logic of Political Violence," Quarterly Journal of Economics, forthcoming.

Blattman, C., and E. Miguel (2010): "Civil War," Journal of Economic Literature, 48(1), 3-57.

Bleakley, H. (2007): "Disease and Development: Evidence from Hookworm Eradication in the American South," Quarterly Journal of Economics, 122(1), 73-117.

Bleakley, H., and F. Lange (2009): "Chronic Disease Burden and the Interaction of Education, Fertility, and Growth," Review of Economics and Statistics, 91(1), 52-65.

BrüCkner, M. (2010): "Population Size and Civil Conflict Risk: Is There A Causal Link?," Economic Journal, 120(544), 535-550.

Cervellati, M., U. Sunde, and S. Valmori (2011): "Spatial Distribution of Infectious Diseases and Differences in Extrinsic Mortality Across Countries," mimeo.

Ciccone, A. (2009): "Transitory Economic Shocks and Civil Conflict," mimeo, CREI.

Collier, P., And A. Hoeffler (1998): "On economic causes of civil war," Oxford Economic Papers, 50(4), 563-573.

$13-28$.

(2002): "On the incidence of civil war in Africa," Journal of Conflict Resolution, 46(1),

(2004): "Greed and Grievance in Civil War," Oxford Economic Papers, 56(4), 563-595.

Collier, P., A. Hoeffler, And D. Rohner (2009): "Beyond Greed and Grievance: Feasibility and Civil War," Oxford Economic Papers, 61(1), 1-27.

Cutler, D., A. Deaton, And A. Lleras-Muney (2006): "The Determinants of Mortality," Journal of Economic Perspectives, 20(4), forthcoming.

Desmet, K., I. Ortuno-Ortin, and R. Wacziarg (2009): "The Political Economy of Ethnolinguistic Cleavages," NBER Working Paper, (15360).

Doyle, M. W., And N. Sambanis (2000): "International peacebuilding: A theoretical and quantitative analysis," American Political Science Review, 94(4), 779-802.

Fearon, J. D. (2005): "Primary Commodity Exports and Civil War," Journal of Conflict Resolution, 49(4), 483-507. 
Fearon, J. D., And D. D. Laitin (2003): "Ethnicity, Insurgency, and Civil War," American Political Science Review, 97(1), 75-90.

Gleditsch, N. P., P. Wallensteen, M. Eriksson, M. Sollenberg, and H. Strand (2002): "Armed Conflict 1946-2001: A New Dataset," Journal of Peace Research, 39(5), 615-637.

Gopinath, R., M. Ostrowski, S. J. Justement, A. S. Fauci, and T. B. Nutman (2000): "Filarial infections increase susceptibility to human immunodeficiency virus infection in peripheral blood mononuclear cells in vitro.," Journal of Infectious Diseases, 182, 1804-1808.

Grossman, H. I., And M. KIm (1995): "Swords or Plowshares? A Theory of the Security of Claims to Property," Journal of Political Economy, 103(6), 1275-1288.

Gubler, D. J. (1991): "Insects in Disease Transmission," in Hunter's Tropical Medicine and Emerging Infectious Diseases. 7 edn.

(1998): "Resurgent Vector-Borne Diseases as a Global Health Problem," Emerging Infectious Diseases, 4(3), 442-450.

Guernier, V., M. Hochberg, and J.-F. Guegan (2004): "Ecology Drives the World-Wide Distribution of Diseases," PLoS Biology, 2, 740-746.

Harbom, L., and P. Wallensteen (2010): "Armed Conflict 1946-2009," Journal of Peace Research, 47(4), 577-587.

Jayachandran, S., And A. Lleras-Muney (2009): "Life Expectancy and Human Capital Investments: Evidence from Maternal Mortality Declines," Quarterly Journal Economics, 124(1), 349-398.

Karp, C., And P. Auwaerter (2007): "Coinfection with HIV and tropical infectious diseases. I. Protozoal pathogens.," Clinical Infectious Diseases, 45(9), 1208-1213.

Lammers, J., and S. van Wijnbergen (2008): "HIV/AIDS, Risk Aversion and Intertemporal Choice," Tinbergen Institute Discussion Paper, 2007-098/1.

Lorentzen, P., J. McMillan, and R. Wacziarg (2008): "Death and Development," Journal of Economic Growth, 13(2), 81-124.

Miguel, Edward, S. S., And E. Sergenti (2004): "Economic Shocks and Civil Conflict: An Instrumental Variables Approach," Journal of Political Economy, 112(4), 725-753.

Mirovsky, J., And C. Ross (1998): "Education, Personal Control, Lifestyle and Health - A Human Capital Hypothesis," Research on Ageing, 20, 415-449.

Montalvo, J. G., and M. Reynal-Querol (2005a): "Ethnic diversity and economic development," Journal of Development Economics, 76(2), 293-323.

(2005b): "Ethnic Polarization, Potential Conflict, and Civil Wars," American Economic Review, 95(3), 796-816.

Sachs, J. D., AND A. M. Warner (1995): "Natural Resource Abundance and Economic Growth," NBER Working Paper, 5398.

Smith, C. F., D. F. Sax, S. D. Gaines, V. Guernier, and J.-F. Guegan (2007): "Globalization of Human Infectious Disease," Ecology, 88(8), 1903-1910. 
Smith, J. P. (1999): "Healthy Bodies and Thick Wallets: The Dual Relation Between Health and Economic Status," Journal of Economic Perspectives, 13(2), 145-166.

SoAres, R. (2005): "Mortality Reductions, Educational Attainment, and Fertility Choice," American Economic Review, 95(3), 580-601.

Stanley, M., P. F. Sparling, M. A. Hamburg, D. A. Relman, E. R. Choffnes, and A. MACK (2008): "Vector-Borne Diseases: Understanding the Environmental, Human Health, and Ecological Connections, Workshop Summary (Forum on Microbial Threats)," .

United_Nations (2006): "World Population Prospects," United Nations, Population Division, New York.

van den Berg, G., M. Lindeboom, and F. Portrait (2006): "Economic Conditions Early in Life and Individual Mortality," American Economic Review, 96(1), 290-302.

WAng, L. (2003): "Determinants of Child Mortality in LDCs - Empirical Findings from Demographic and Health Surveys," Health Policy, 65(3), 277-299.

WHO (2008): World Health Organization, World Health Report 2008. 
Tables and Figures 
Figure 1: Civil Conflicts and Disease Richness

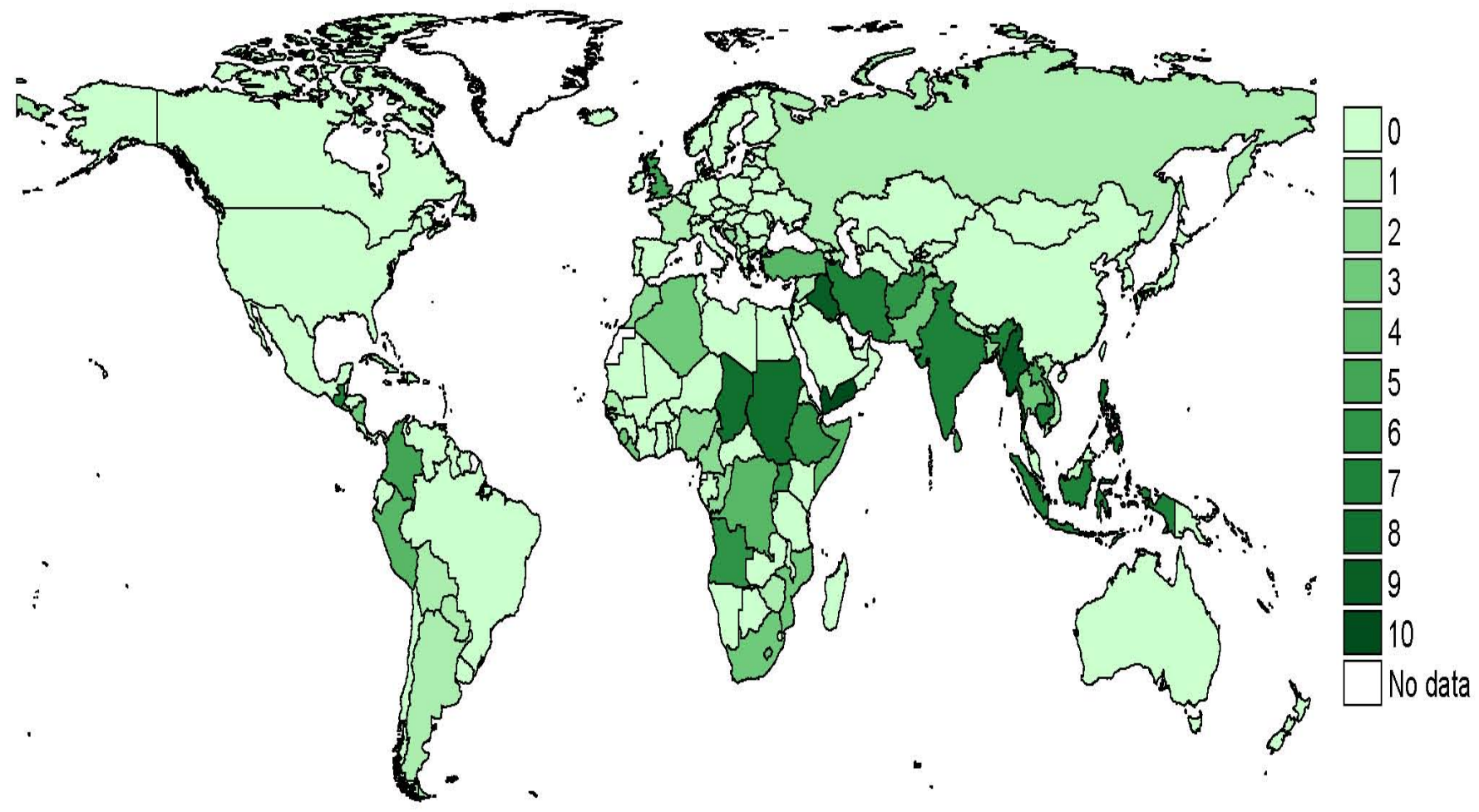

(a) Civil War (PRIO)

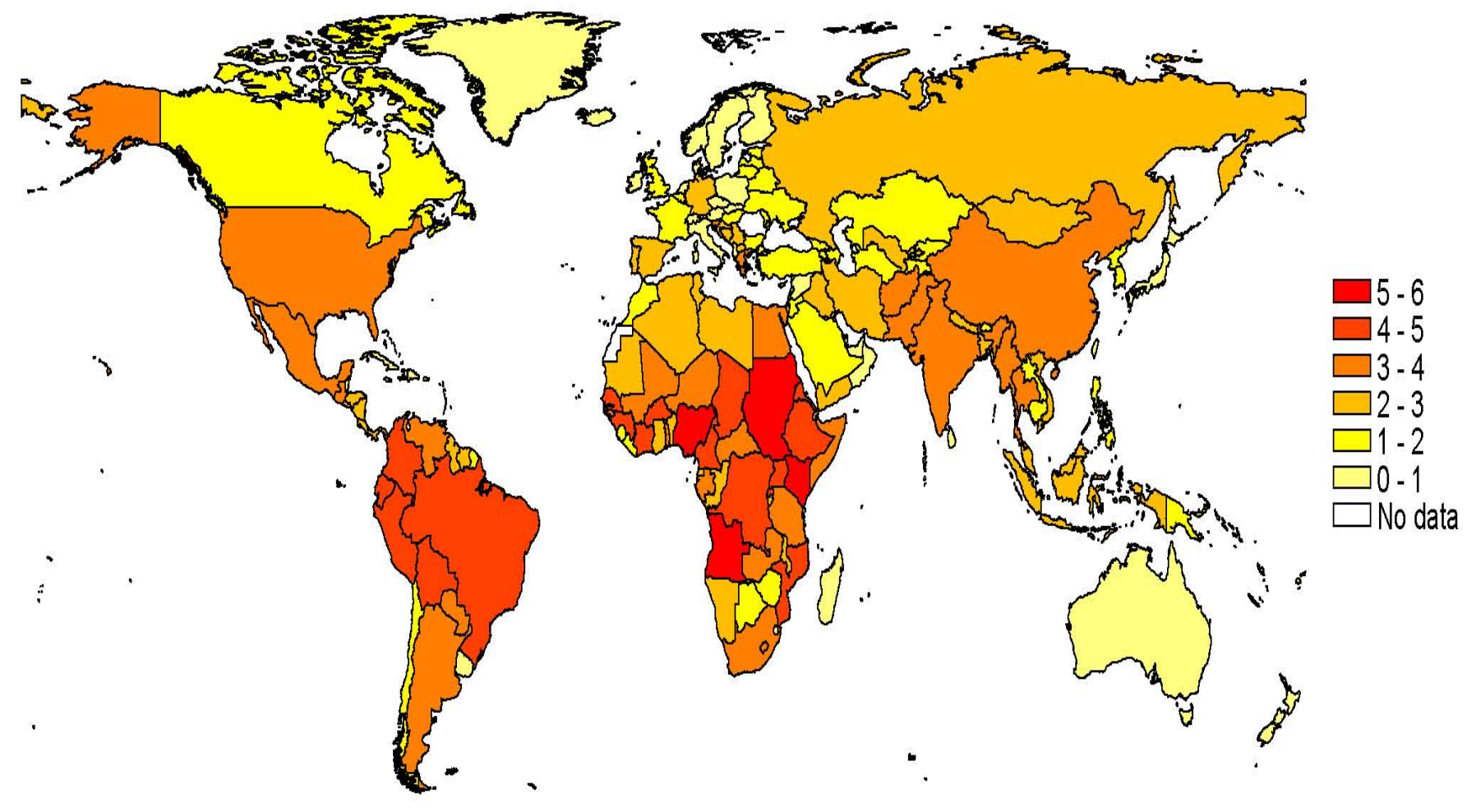

(b) Disease Richness (Deadly)

Number of five-year periods with at least one conflict according to the definition "Civil War (PRIO)" in the period 1960-2005 and "Disease Richness (Deadly)". See Section 2 for details. 
Figure 2: Temperature, Latitude and Disease Richness

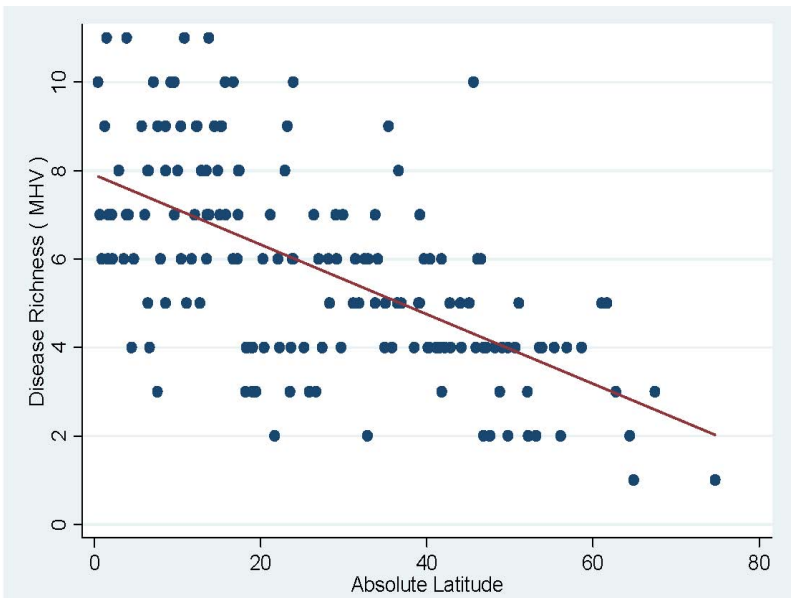

(a) Absolute latitude and Disease Richness

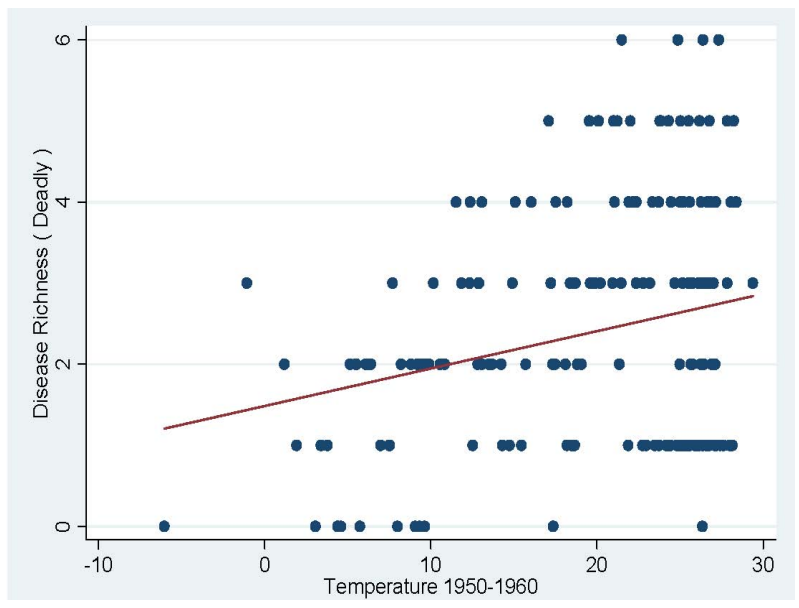

(b) Temperatures and Disease Richness

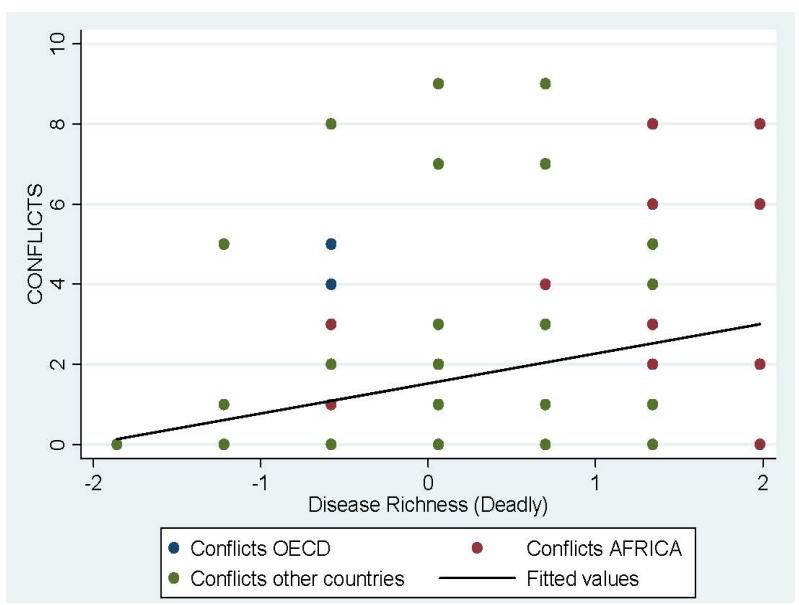

(c) Disease Richness and Conflicts

Panel (a) presents a scatter plot of the relation between absolute latitude and the measure "Disease Richness (Deadly)"; Panel (b) presents a scatter plot of the relation between average temperature 1950-1960 and "Disease Richness (Deadly)"; Panel (c) presents a scatter plot for "Disease Richness (Deadly)" and the number of five-year periods with at least one conflict according to the variable "Civil War (PRIO)". See Section 2 for details. 
Table 1: Summary Information on Multi-Host Vector-Transmitted Infectious Agents, MHV

\begin{tabular}{|c|c|c|c|c|}
\hline Infectious Agent & Vector Host & $\begin{array}{l}\text { Spread/ } \\
\text { \%Countries }\end{array}$ & Eradication & Notes \\
\hline Angiomatoses & $\begin{array}{l}\text { cat flea; tick (ixodid) - } \\
\text { rare }\end{array}$ & $\begin{array}{l}\text { Wide / } \\
100 \%\end{array}$ & Not eradicable & $\begin{array}{l}\text { The incidence of bacillary angiomatosis is expected to increase as } \\
\text { the HIV epidemic accelerates. }\end{array}$ \\
\hline Relapsing fever & $\begin{array}{l}\text { tick Ornithodoros, } \\
\text { louse Pediculus }\end{array}$ & $\begin{array}{l}\text { Medium / } \\
52 \%\end{array}$ & No & Mortality rate is $1 \%$ with treatment; $30-70 \%$ without treatment. \\
\hline Malaria & mosquito (Anopheles) & Large / 77\% & $\begin{array}{l}\text { Now not eradicable } \\
\text { Globally. Regional } \\
\text { eradication possible. }\end{array}$ & $\begin{array}{l}>300 \text { million cases; > 1million deaths. Drug and insecticide } \\
\text { resistance. Malaria elimination has been achieved in the USA, } \\
\text { Australia and Western Europe. }\end{array}$ \\
\hline $\begin{array}{l}\text { Onchocerciasis } \\
\text { (River blindness) }\end{array}$ & $\begin{array}{l}\text { mosquito (Anopheles } \\
\text { funestus and An. } \\
\text { gambiae) }\end{array}$ & Low / 18\% & $\begin{array}{l}\text { Yes regionally. } \\
\text { Globally } \\
\text { Difficult }\end{array}$ & $\begin{array}{l}37-40 \text { million cases; } 340.00 \text { blind. } \\
\text { Onchocerciasis is currently endemic in } 30 \text { African countries, Yemen, } \\
\text { and isolated regions of South America. } 99 \% \text { of onchocerciasis cases } \\
\text { occur in Africa. About } 18 \text { million people are currently infected with } \\
\text { this parasite; approximately } 300,000 \text { have been permanently } \\
\text { blinded. Elimination is under way in the region of the Americas, } \\
\text { where this disease is endemic to Brazil, Colombia, Ecuador, } \\
\text { Guatemala, Mexico and Venezuela. }\end{array}$ \\
\hline Dengue & $\begin{array}{l}\text { Aedes aegypti, A. } \\
\text { albopictus, } \\
\text { Apolynesiensis, A. } \\
\text { scutellaris }\end{array}$ & $\begin{array}{l}\text { Medium / } \\
51 \%\end{array}$ & No & $\begin{array}{l}\text { Dengue is endemic in at least } 100 \text { countries in Asia, the Pacific, the } \\
\text { Americas, Africa, and the Caribbean. Epidemic dengue has become } \\
\text { more common since the } 1980 \text { s. Outbreaks register thousand of } \\
\text { cases. }\end{array}$ \\
\hline Yellow fever & $\begin{array}{l}\text { mosquito (Aedes, } \\
\text { Haemagogus, } \\
\text { Sabethes), monkey, ? } \\
\text { marsupial }\end{array}$ & Low / 22\% & Not now eradicable & $\begin{array}{l}\text { Eradication difficult for the sylvatic Reservoir. Heat-labile vaccine. } \\
\text { Endemic in tropical and subtropical areas of South America and } \\
\text { Africa. A vaccine has existed since the middle of the 20th century } \\
\text { and some countries require vaccinations for travelers. Since no } \\
\text { therapy is known, vaccination programs are key. Since the } 1980 \text { s, } \\
\text { the number of cases of yellow fever has been increasing, making it a } \\
\text { reemerging disease. }\end{array}$ \\
\hline $\begin{array}{l}\text { Leishmaniasis- } \\
\text { cutaneous }\end{array}$ & $\begin{array}{l}\text { Fly (sandfly } \\
\text { Phlebotomus for old } \\
\text { world; Lutzomyia or } \\
\text { Psychodopygus for } \\
\text { new world) }\end{array}$ & $\begin{array}{l}\text { Medium / } \\
39 \%\end{array}$ & No & $\begin{array}{l}\text { Endemic to many parts of the world, its distribution is tightly linked } \\
\text { to geography. It may appear on the skin of affected individuals up to } \\
20 \text { years after being partially treated, untreated or even in those } \\
\text { considered adequately treated. Almost all the treatment options are } \\
\text { toxic with significant side-effects. }\end{array}$ \\
\hline $\begin{array}{l}\text { Leishmaniasis- } \\
\text { mucocutaneous }\end{array}$ & $\begin{array}{l}\text { fly (sandfly = } \\
\text { Lutzomyia or } \\
\text { Psychodopygus) }\end{array}$ & $\begin{array}{l}\text { Very } \\
\text { Limited / } \\
8.1 \%\end{array}$ & No & $\begin{array}{l}\text { It is treated with long therapies (e.g. } 30 \text { days) but up to } 42 \% \text { of } \\
\text { patients fail to be cured. Even in those patients who achieve an } \\
\text { apparent cure it relapses in } 19 \% \text { of cases. Spread in central and } \\
\text { South America. }\end{array}$ \\
\hline $\begin{array}{l}\text { Leishmaniasis- } \\
\text { visceral }\end{array}$ & $\begin{array}{l}\text { fly (sandfly = } \\
\text { Phlebotomus for old } \\
\text { world; Lutzomyia for } \\
\text { new world) }\end{array}$ & $\begin{array}{l}\text { Medium / } \\
49 \%\end{array}$ & Not now eradicable & $\begin{array}{l}500,000 \text { cases. Difficult control of vector breeding places. } \\
\text { Neglected disease. Is the second-largest parasitic killer in the world } \\
\text { (after malaria), responsible for an estimated 500,000 cases each } \\
\text { year worldwide. Treatments exist but most of them are costly } \\
\text { and/or toxic. }\end{array}$ \\
\hline $\begin{array}{l}\text { Trypanosomiasis- } \\
\text { African }\end{array}$ & $\begin{array}{l}\text { fly Glossina }=\text { tsetse } \\
\text { fly } \\
\text { brucei gambiense and } \\
\text { Try. [T.] rhodesiense }\end{array}$ & Low / 16\% & Not eradicable & $\begin{array}{l}\text { Difficult elimination of reservoir host, difficult treatment and } \\
\text { diagnosis. Neglected disease. Endemic in Sub-Saharan Africa, } \\
\text { covering about } 36 \text { countries and } 60 \text { million people. It is estimated } \\
\text { that } 300,000 \text { to } 600,000 \text { people are currently infected, the number } \\
\text { having declined somewhat in recent years. Four major epidemics } \\
\text { have occurred in recent history, one lasting from } 1896-1906 \text { and } \\
\text { the other two in } 1920 \text { and } 1970 \text {. Epidemic in } 2008 \text { in Uganda. }\end{array}$ \\
\hline $\begin{array}{l}\text { Trypanosomiasis- } \\
\text { American }\end{array}$ & $\begin{array}{l}\text { bug Triatome or } \\
\text { 'kissing' bug = } \\
\text { Panstrongylus, } \\
\text { Rhodnius and } \\
\text { Triatoma spp. }\end{array}$ & $\begin{array}{l}\text { Very } \\
\text { limited / } \\
9.4 \%\end{array}$ & $\begin{array}{l}\text { Not Eradicable. } \\
\text { Potential for limiting } \\
\text { transmission }\end{array}$ & $\begin{array}{l}\text { Neglected disease. Endemic exclusively in the Americas, particularly } \\
\text { in rural areas of Mexico, Central America, and South America. A } \\
\text { reduction by } 72 \% \text { of the incidence of human infection in children } \\
\text { and young adults has been registered, and at least two countries } \\
\text { (Uruguay, in 1997, and Chile, in 1999) have been certified free of } \\
\text { vectorial and transfusional transmission. In Argentina vectorial } \\
\text { transmission has been interrupted in } 13 \text { of the } 19 \text { endemic } \\
\text { provinces. }\end{array}$ \\
\hline $\begin{array}{l}\text { Filariasis-Brugia } \\
\text { malayi }\end{array}$ & $\begin{array}{l}\text { mosquito (Mansonia, } \\
\text { Aedes, Anopheles) }\end{array}$ & $\begin{array}{l}\text { Very } \\
\text { limited / } \\
6.3 \% \\
\end{array}$ & $\begin{array}{l}\text { Potentially } \\
\text { Eradicable }\end{array}$ & $\begin{array}{l}120 \text { million cases (all Lymphatic Filariasis). } \\
\text { Overall, of } 83 \text { endemic countries, mass treatment has been rolled } \\
\text { out in } 48 \text {, and elimination of transmission reportedly achieved in } 21 .\end{array}$ \\
\hline Typhus-epidemic & $\begin{array}{l}\text { louse Pediculus, } \\
\text { squirrel flea (?) }\end{array}$ & Low / $27 \%$ & Not now eradicable & $\begin{array}{l}\text { Vaccine developed during World War II. Epidemics have usually } \\
\text { occurred in Eastern Europe, the Middle East and parts of Africa. } \\
\text { Since 1971, Typhus exanthematicus (classical typhus) has not } \\
\text { appeared in Bosnia and Herzegovina, so epidemic typhus can be } \\
\text { considered as an eradicated communicable disease in that country. }\end{array}$ \\
\hline
\end{tabular}

Sources: Global Infectious Disease and Epidemiology Network, GIDEON; http://www.gideononline.com. Data downloaded from the database in July 2009. Report of the International Task Force for Disease Eradication (1993, updated in 2008). See text for details. 
Table 2: Characteristics of Deadly Multi-Host Vector-Transmitted Diseases

\begin{tabular}{|c|c|c|c|c|c|c|}
\hline & $\begin{array}{l}\text { Typhus } \\
\text { Epidemic }\end{array}$ & $\begin{array}{c}\text { Relapsing } \\
\text { Fever }\end{array}$ & $\begin{array}{l}\text { Dengue } \\
\text { Fever }\end{array}$ & $\begin{array}{l}\text { Yellow } \\
\text { Fever }\end{array}$ & $\begin{array}{c}\text { Sleep } \\
\text { Disease }^{1}\end{array}$ & $\begin{array}{c}\text { Black } \\
\text { Fever }^{2}\end{array}$ \\
\hline Agent & bacterium & bacterium & virus & virus & parasite & parasite \\
\hline Vector & body louse & louse, ticks & mosquito & mosquitos & tsetse fly & sandfly \\
\hline Incubation & $1-2$ weeks & 3-18 days & 3-14 days & 3-6 days & weeks-months & weeks-months \\
\hline Mortality & $10-40 \%$ & $30-70 \%$ & 30\% (hem.fev.) & $15-50 \%$ & $100 \%$ & $100 \%$ \\
\hline Cure & antibiotics & antibiotics & none & none & $\operatorname{drugs}^{3}$ & Pentamine \\
\hline Vaccine & yes & none & none & yes & none & none \\
\hline Prevention & insecticides (DDT) & none & insecticides & insecticides & insecticides & none \\
\hline
\end{tabular}

${ }^{1}$ Trypasonomiasis Africanis

${ }^{2}$ Leishmaniasis Visceral

${ }^{3}$ Drugs that are difficult to administer by laypersons. Source: GIDEON.

Table 3: Summary Statistics of Main Variables of Interest

\begin{tabular}{|c|c|c|c|c|c|c|c|c|c|}
\hline & \multicolumn{3}{|c|}{ Baseline Sample } & \multicolumn{3}{|c|}{ No Conflicts } & \multicolumn{3}{|c|}{ Some Conflicts } \\
\hline & Mean & Std. Dev. & Obs. & Mean & Std. Dev. & Obs. & Mean & Std. Dev. & Obs. \\
\hline Civil War (PRIO) & 0.16 & 0.25 & 902 & 0.00 & 0.00 & 567 & 0.43 & 0.50 & 335 \\
\hline Conflict (PRIO) & 0.25 & 0.43 & 902 & 0.08 & 0.27 & 567 & 0.55 & 0.50 & 335 \\
\hline Disease Richness (Deadly) & 2.90 & 1.56 & 902 & 2.45 & 1.52 & 567 & 3.66 & 1.30 & 335 \\
\hline Disease Richness (Deadly End.) & 2.84 & 1.68 & 902 & 2.36 & 1.65 & 567 & 3.66 & 1.38 & 335 \\
\hline Disease Richness (MHV) & 6.19 & 2.50 & 902 & 5.50 & 2.50 & 567 & 7.33 & 2.04 & 335 \\
\hline Droughts & 0.65 & 1.20 & 902 & 0.58 & 1.21 & 567 & 0.79 & 1.17 & 335 \\
\hline Absolute Latitude & 24.53 & 17.27 & 902 & 27.40 & 18.51 & 567 & 19.77 & 13.66 & 335 \\
\hline Log Population Density & 3.48 & 1.38 & 902 & 3.42 & 1.43 & 567 & 3.60 & 1.27 & 335 \\
\hline Log Population Size & 16.01 & 1.55 & 902 & 15.62 & 1.50 & 567 & 16.67 & 1.40 & 335 \\
\hline Log Country Size & 12.52 & 1.67 & 902 & 12.20 & 1.72 & 567 & 13.08 & 1.40 & 335 \\
\hline Ethnic Polarization & 0.52 & 0.24 & 902 & 0.48 & 0.26 & 567 & 0.58 & 0.18 & 335 \\
\hline Log GDP per capita & 7.76 & 1.13 & 902 & 7.96 & 1.17 & 567 & 7.43 & 0.96 & 335 \\
\hline Primary Exporter & 0.14 & 0.14 & 902 & 0.16 & 0.16 & 567 & 0.12 & 0.10 & 335 \\
\hline Mountains & 16.67 & 19.95 & 902 & 15.28 & 19.64 & 567 & 19.03 & 20.28 & 335 \\
\hline Non-Contingent Land & 0.17 & 0.37 & 902 & 0.15 & 0.35 & 567 & 0.2 & 0.40 & 335 \\
\hline Democracy & 0.48 & 0.50 & 902 & 0.53 & 0.50 & 567 & 0.42 & 0.49 & 335 \\
\hline Temperature & 19.36 & 7.40 & 761 & 18.3 & 8.11 & 497 & 21.35 & 5.33 & 264 \\
\hline
\end{tabular}

Statistics based on baseline sample with 902 observations from 110 countries. Classification "No Conflict" / "Some Conflict" refers to criterion Civil War (PRIO) in any single 5-year period between 1960 and 2005.

Table 4: Summary Statistics: Data on Incidence of Civil Conflicts?

\begin{tabular}{|c|c|c|c|c|c|c|}
\hline & \multicolumn{2}{|c|}{ 5-year Period } & \multicolumn{2}{|c|}{ Yearly Data } & \multicolumn{2}{|c|}{ Entire Period } \\
\hline & Mean & Observations & Mean & Observations & Mean & Observations \\
\hline Civil War (PRIO) & 0.162 & 902 & 0.12 & 4568 & 0.183 & 86 \\
\hline Conflict (PRIO) & 0.252 & 902 & 0.16 & 4568 & 0.278 & 86 \\
\hline \multicolumn{7}{|c|}{ Alternative Conflicts Data (Robustness) } \\
\hline Conflict (FL) & 0.188 & 816 & & & 0.163 & 86 \\
\hline Conflict (DS) & 0.168 & 816 & & & 0.156 & 86 \\
\hline Conflict (COW) & 0.111 & 902 & 0.010 & 4762 & 0.129 & 86 \\
\hline
\end{tabular}

The statistics referring to the entire period (cross-section) refers to the number of five years intervals with at least one incidence of Civil War. 


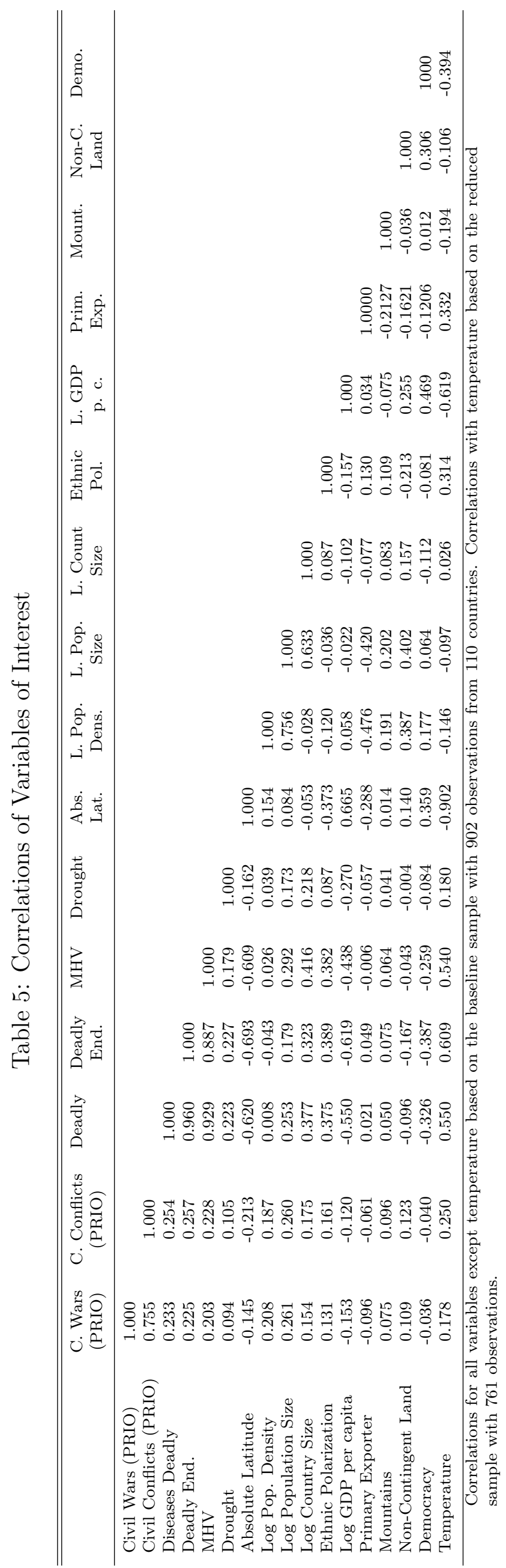




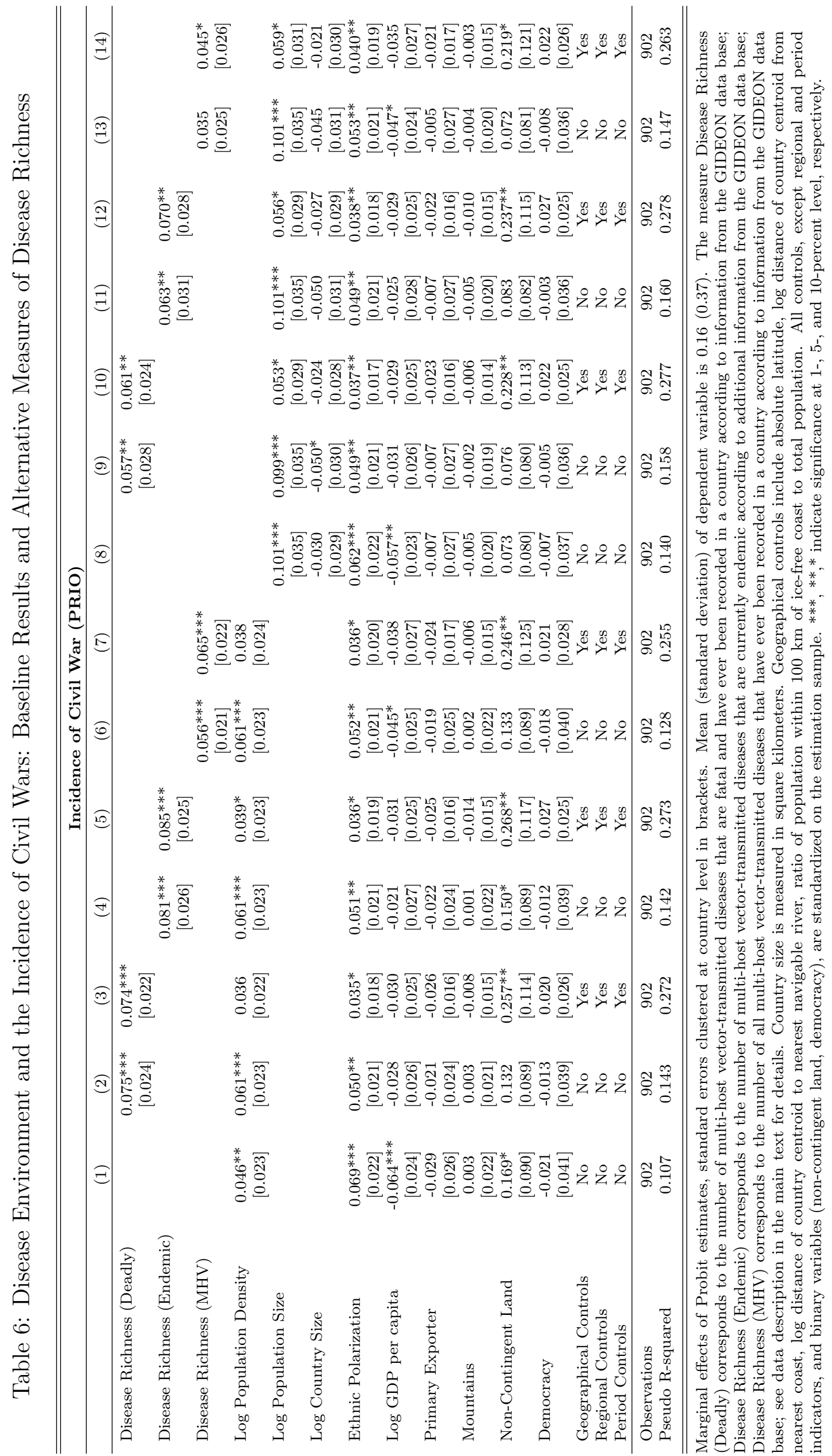




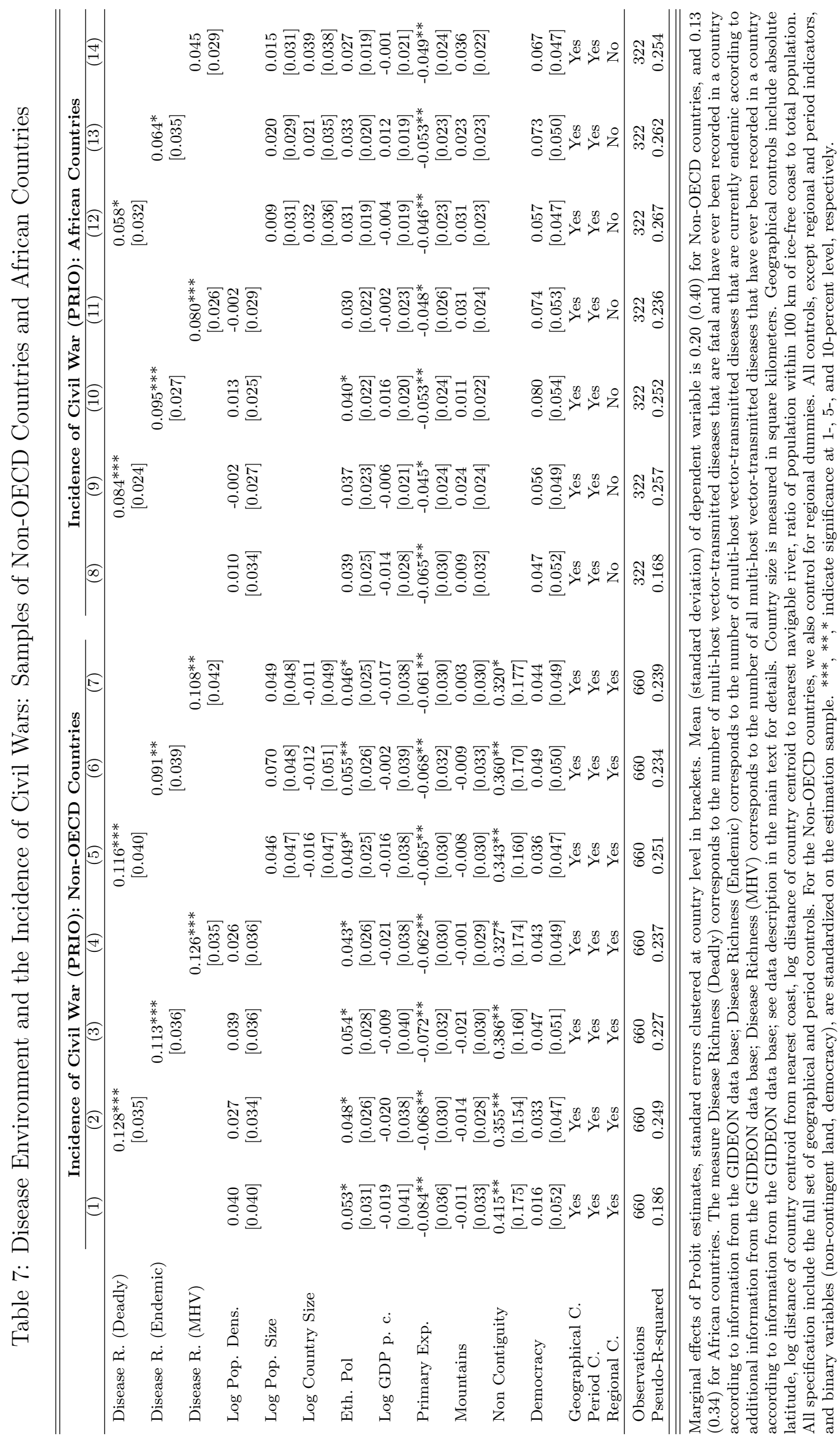




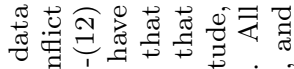

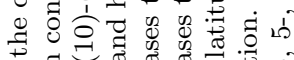

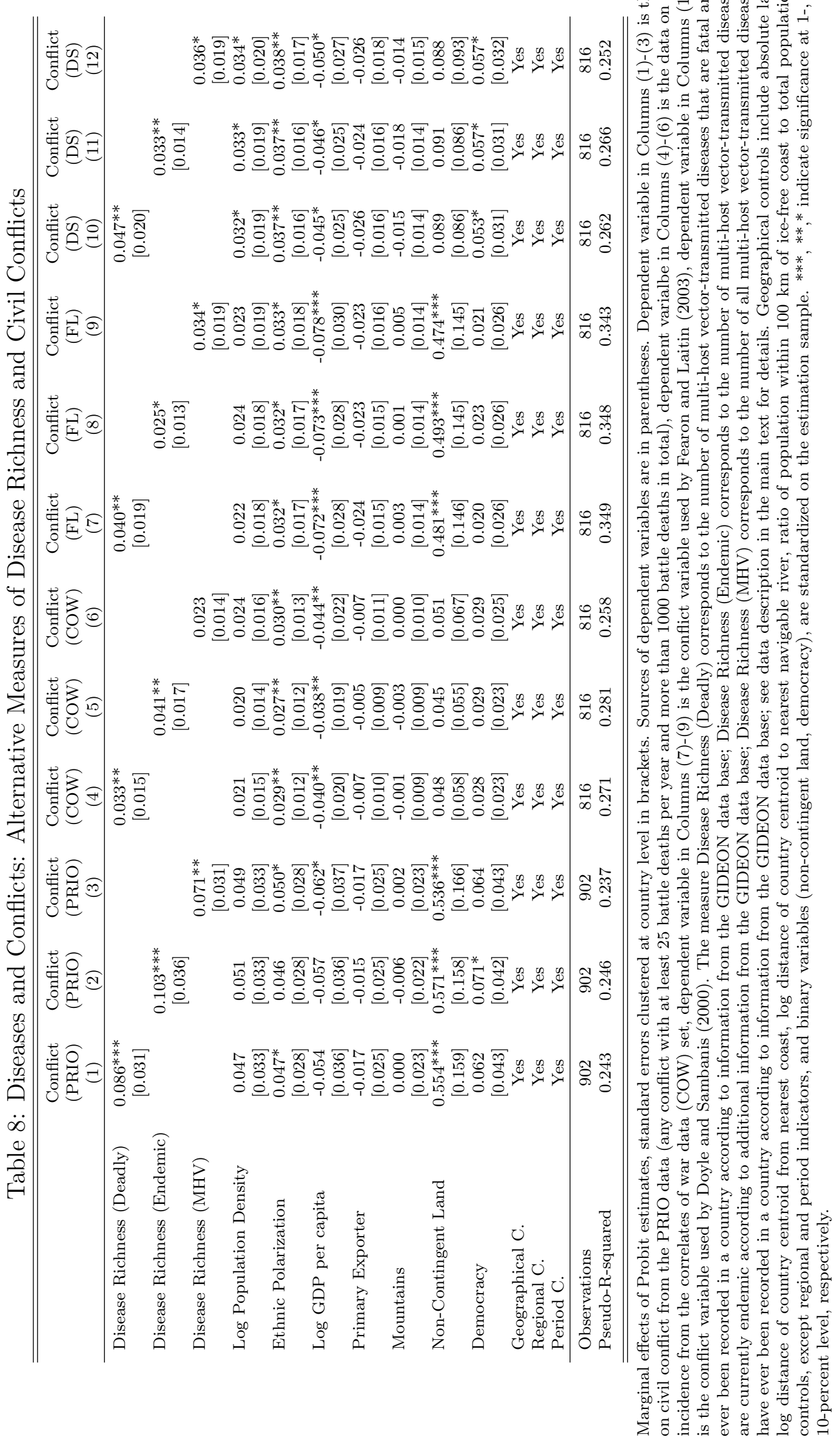




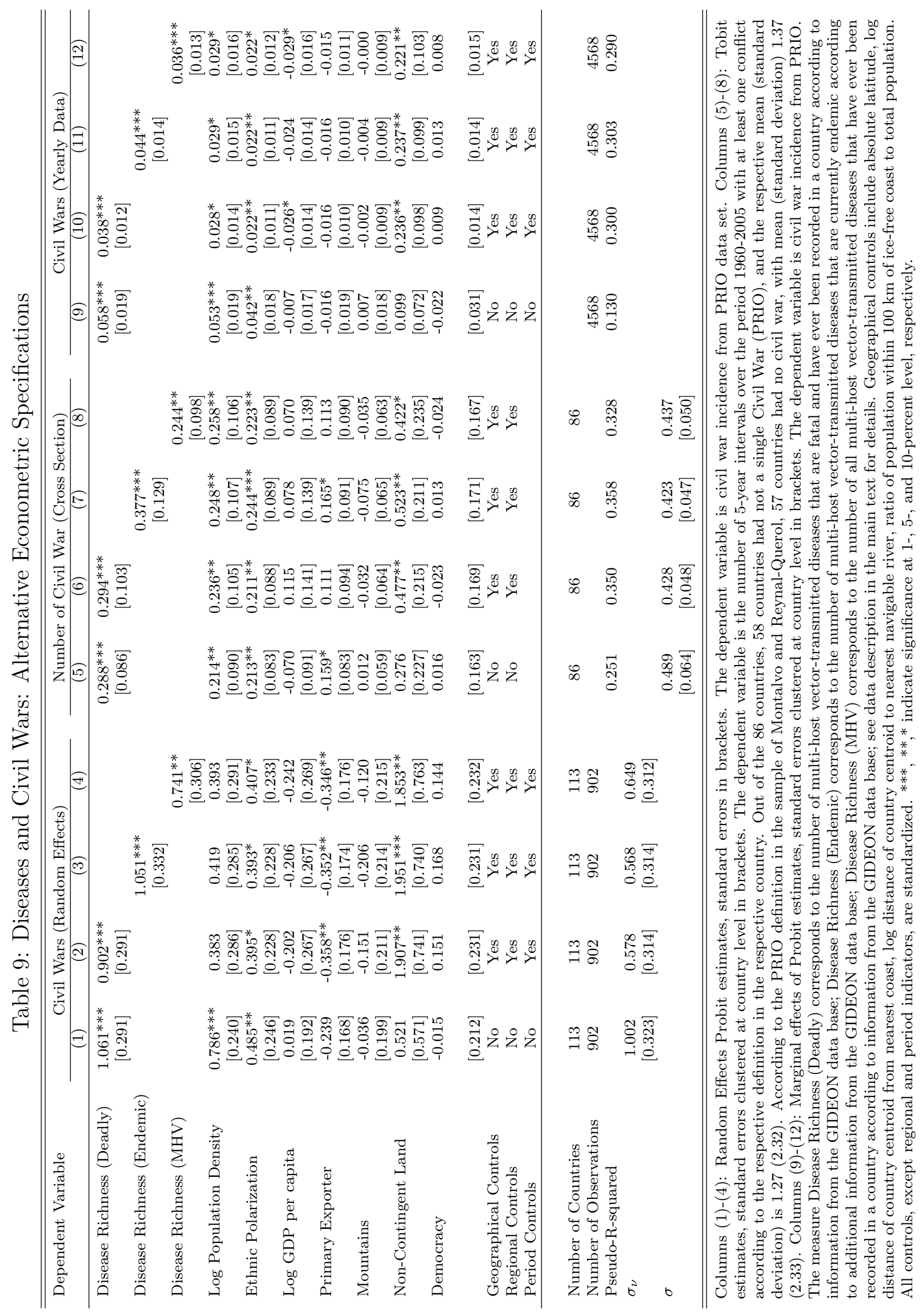




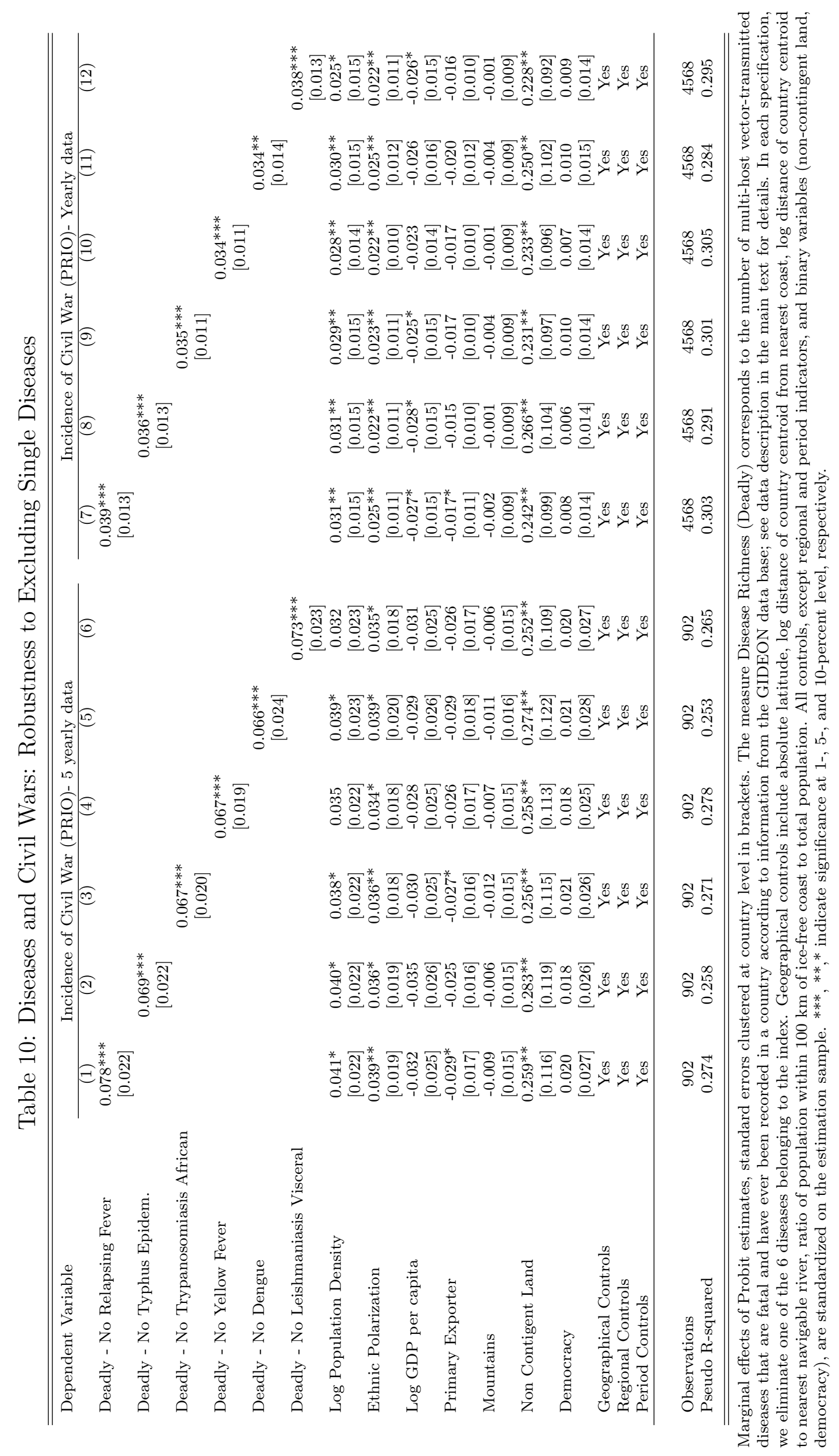




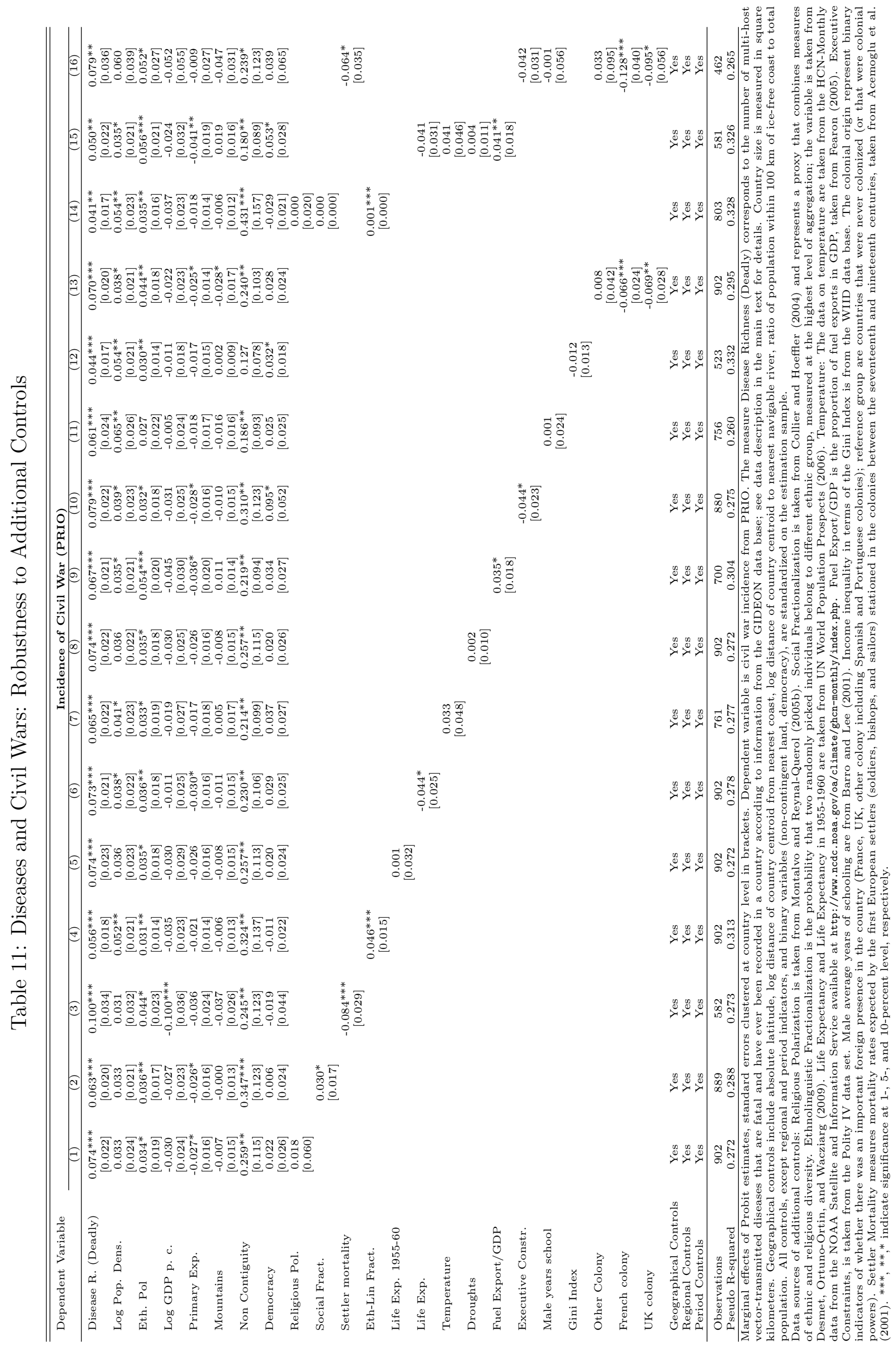




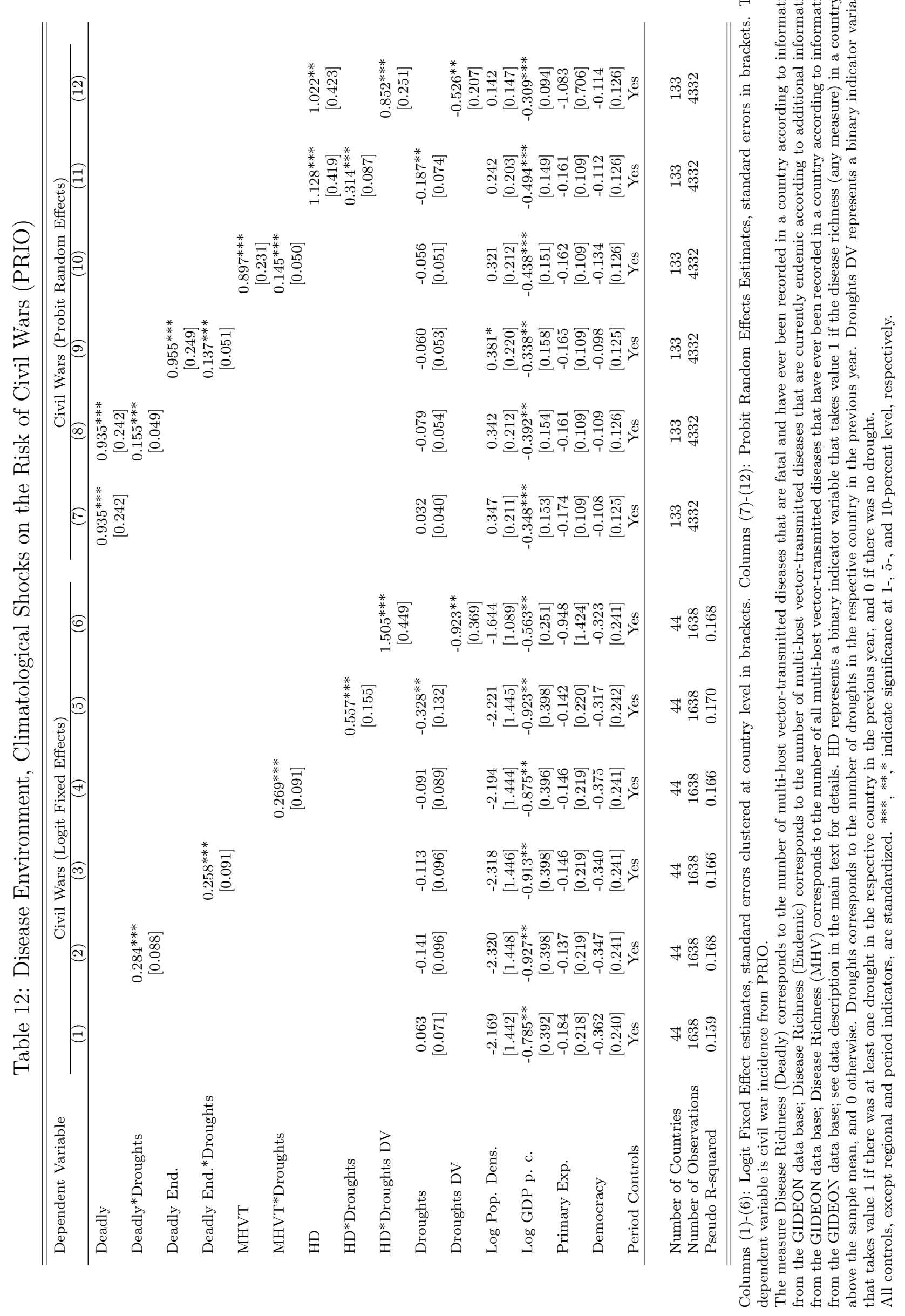




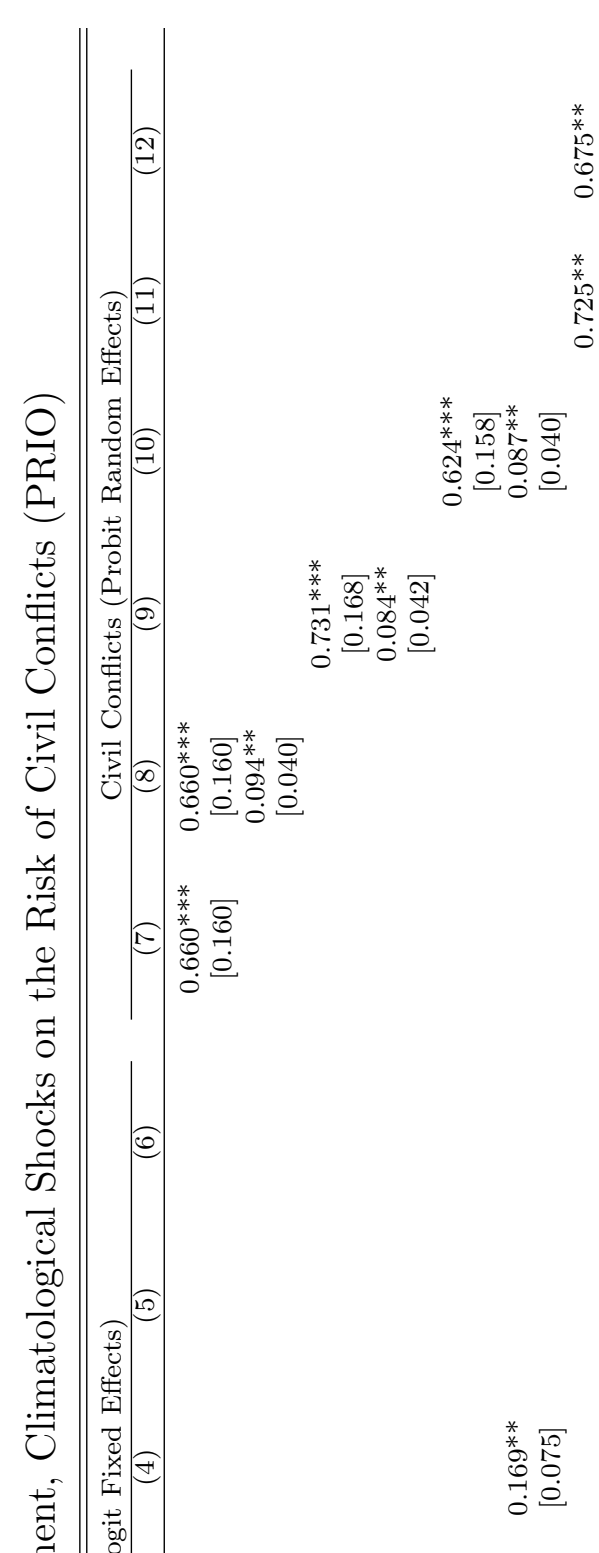

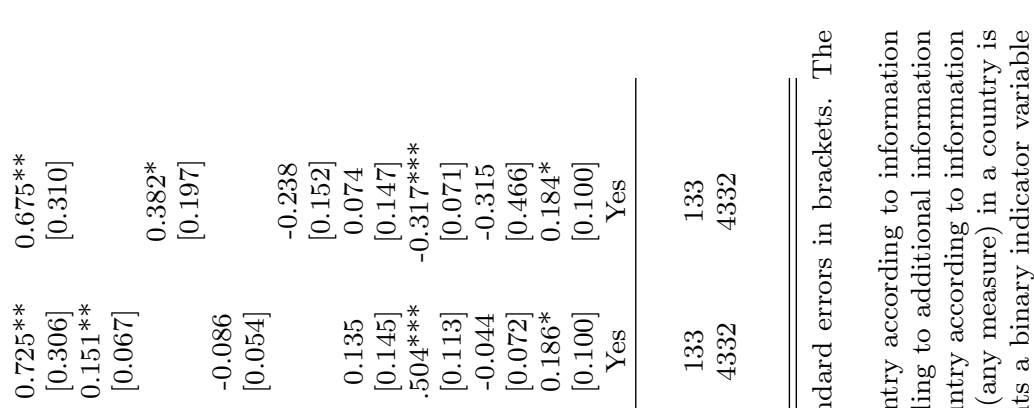

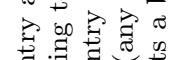

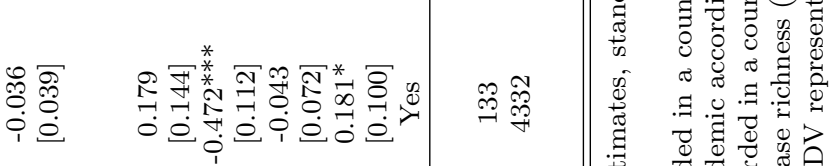

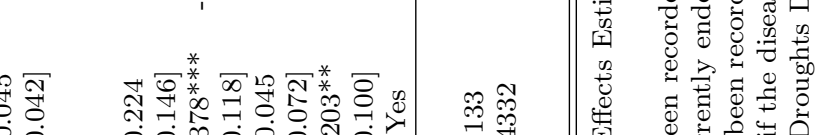
i.

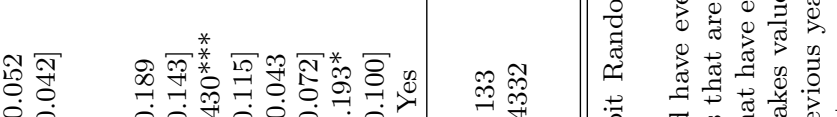

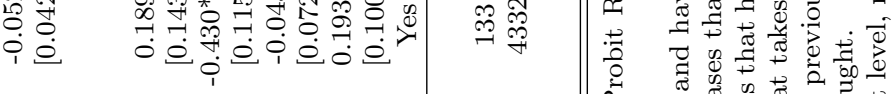

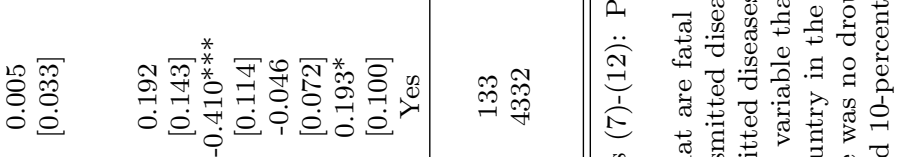

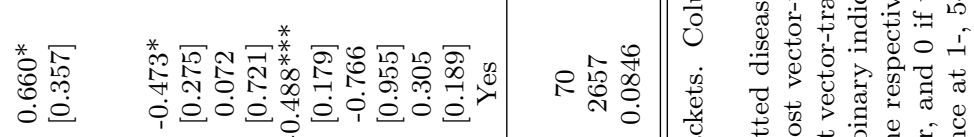

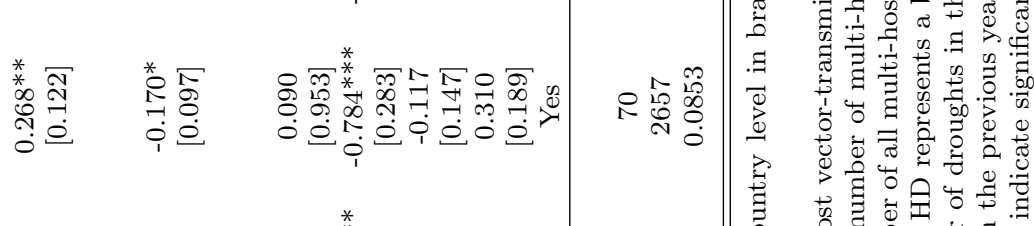

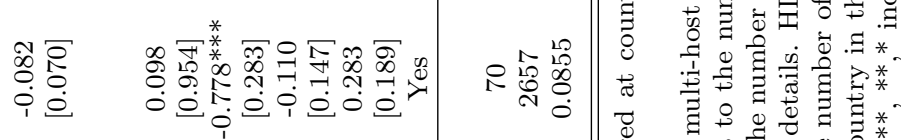

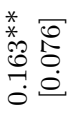

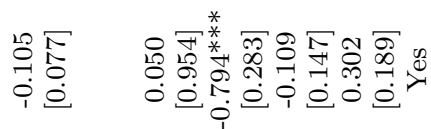
每

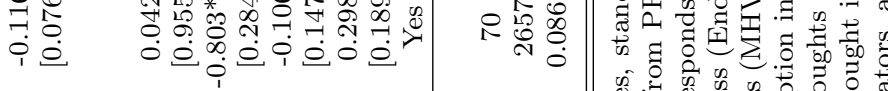

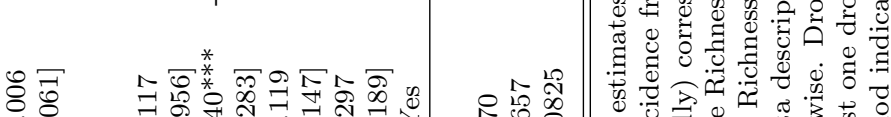

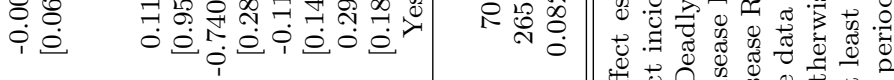
ह

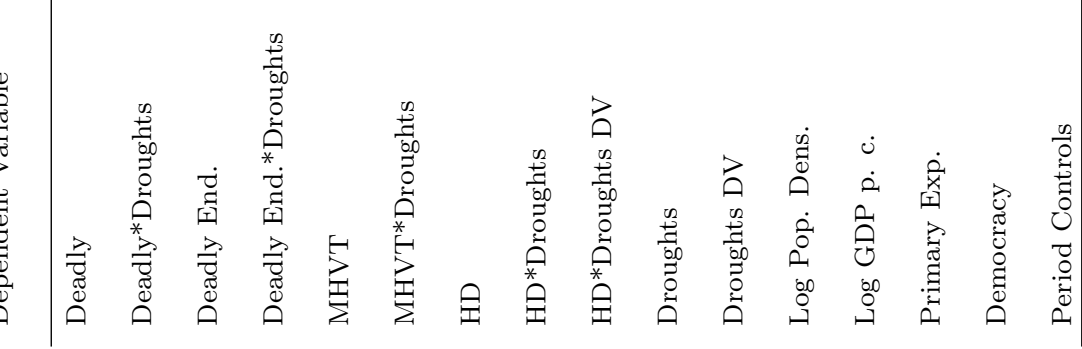

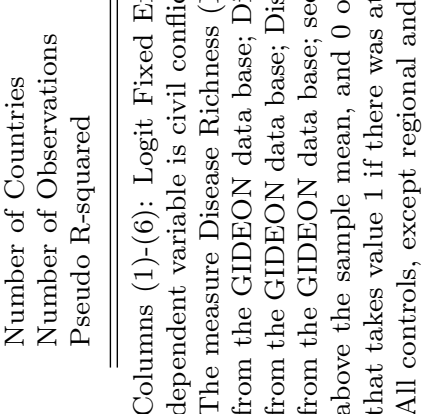


Additional Material Not Intended For Publication 


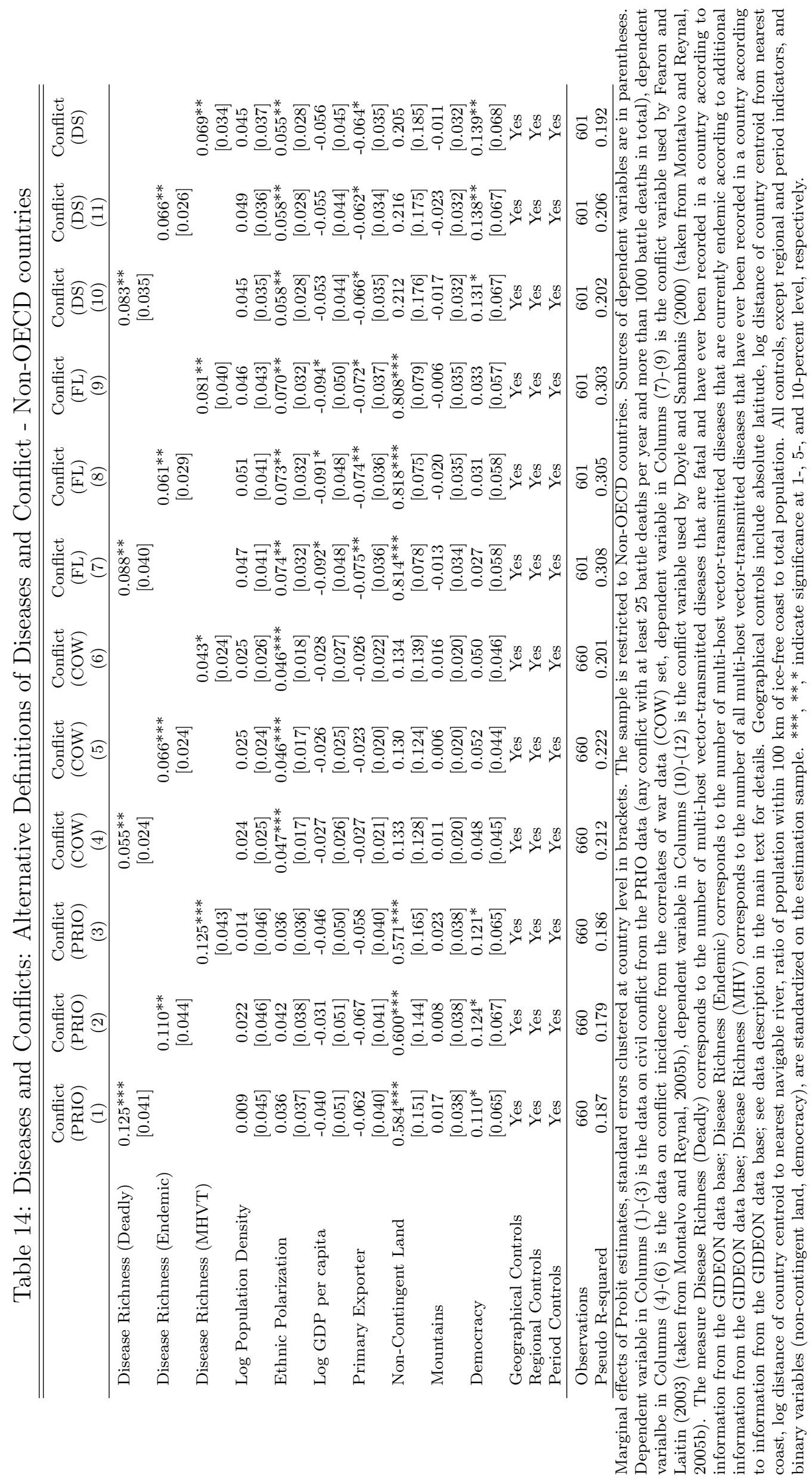




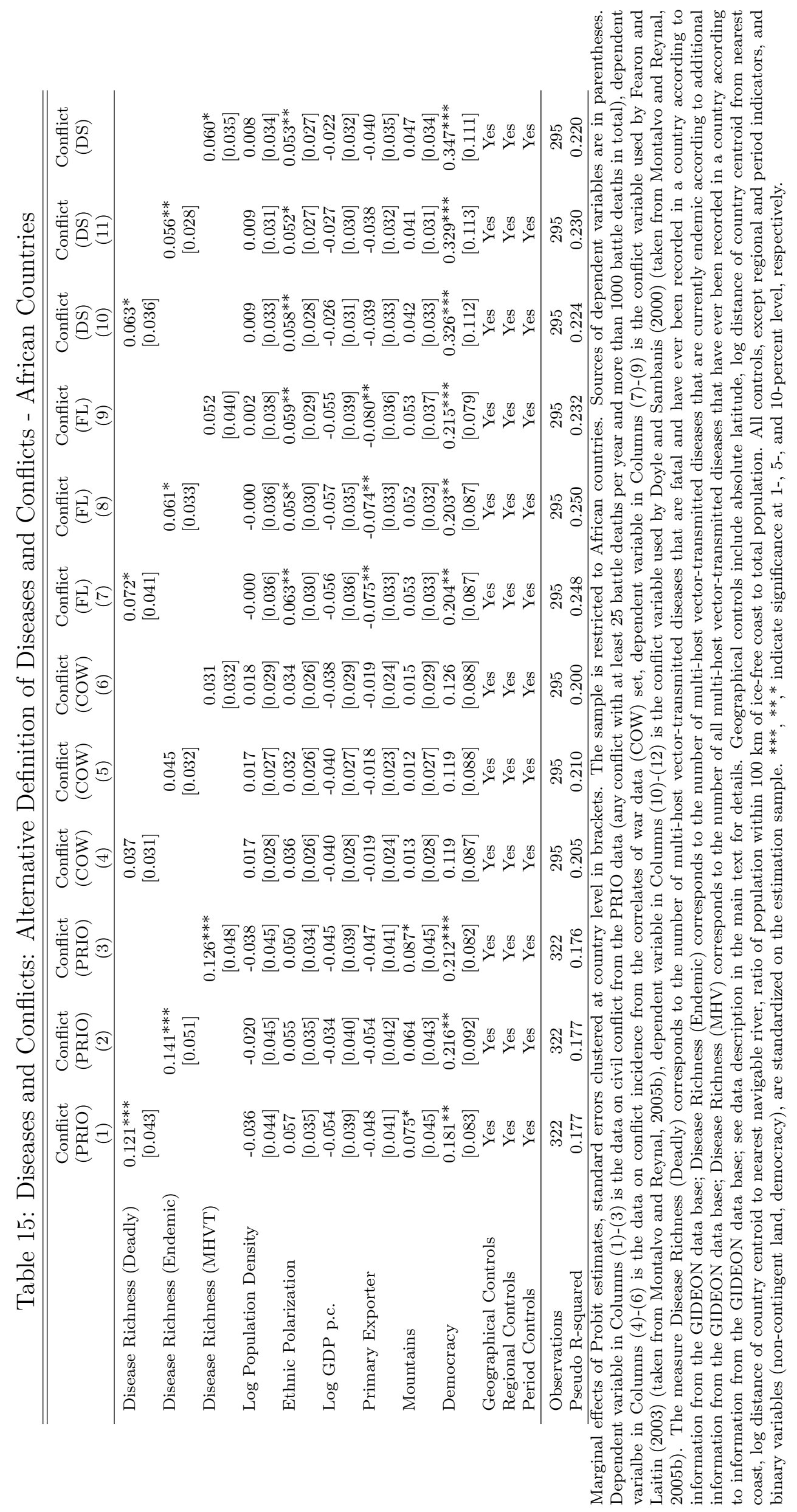




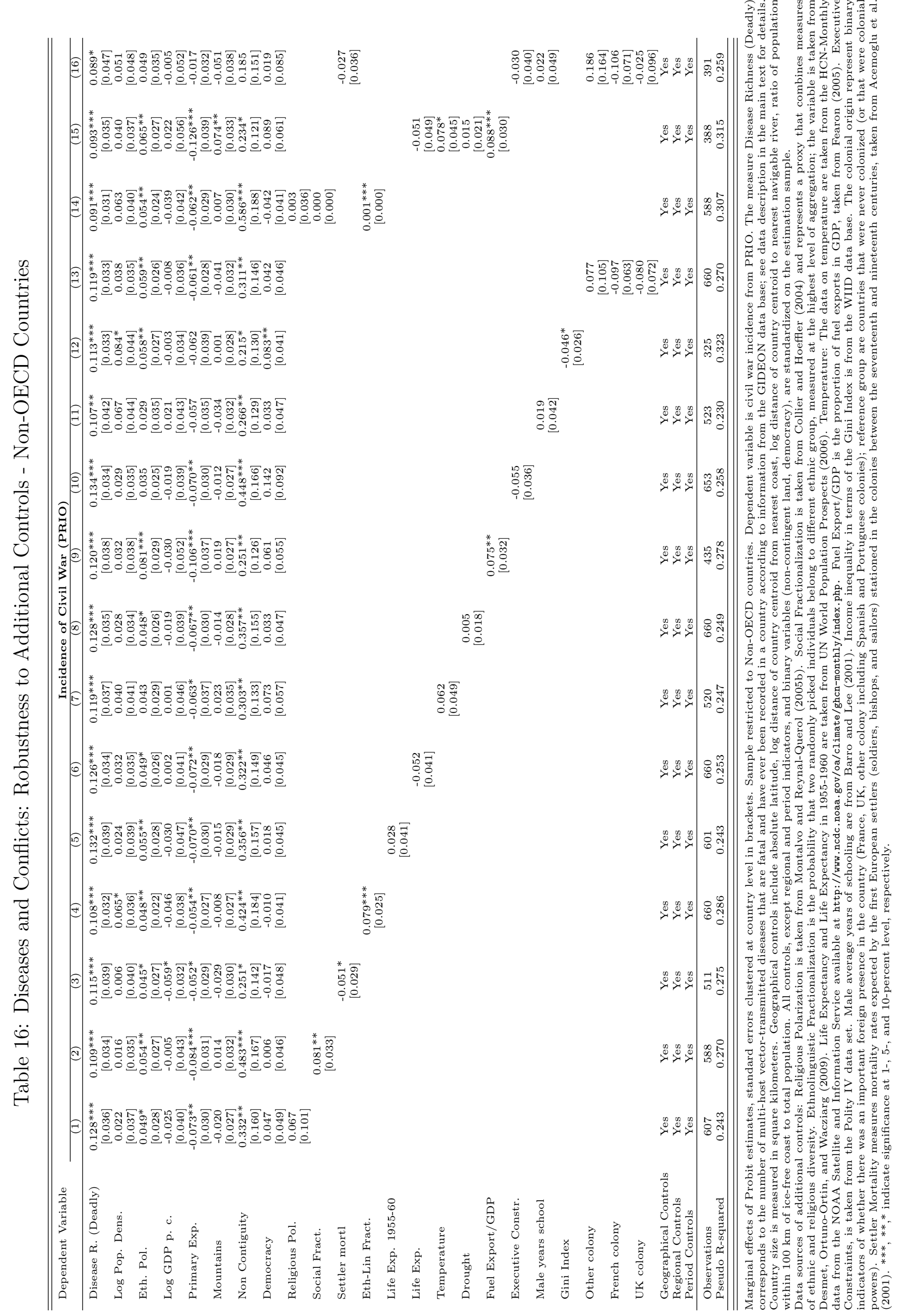




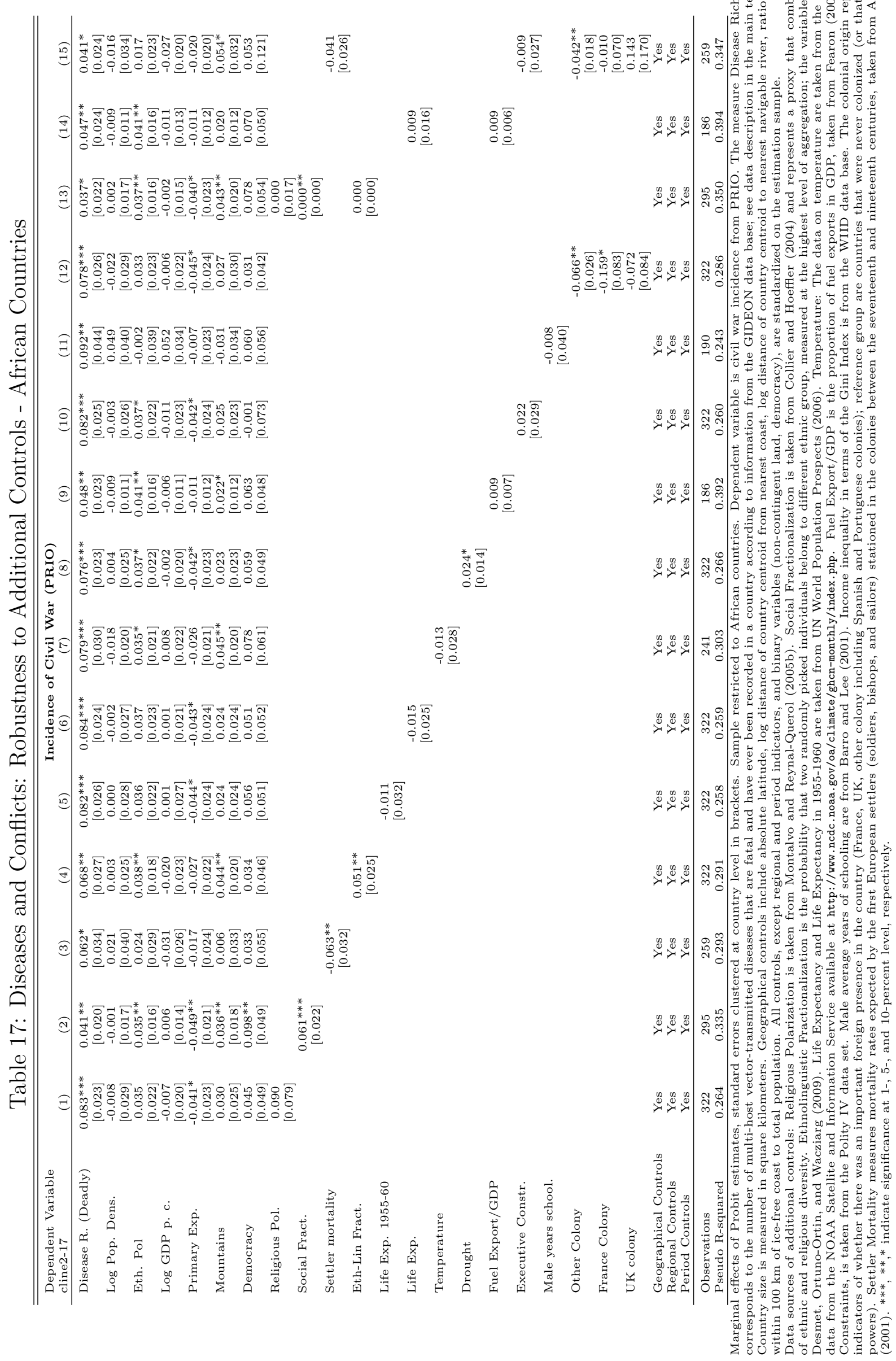



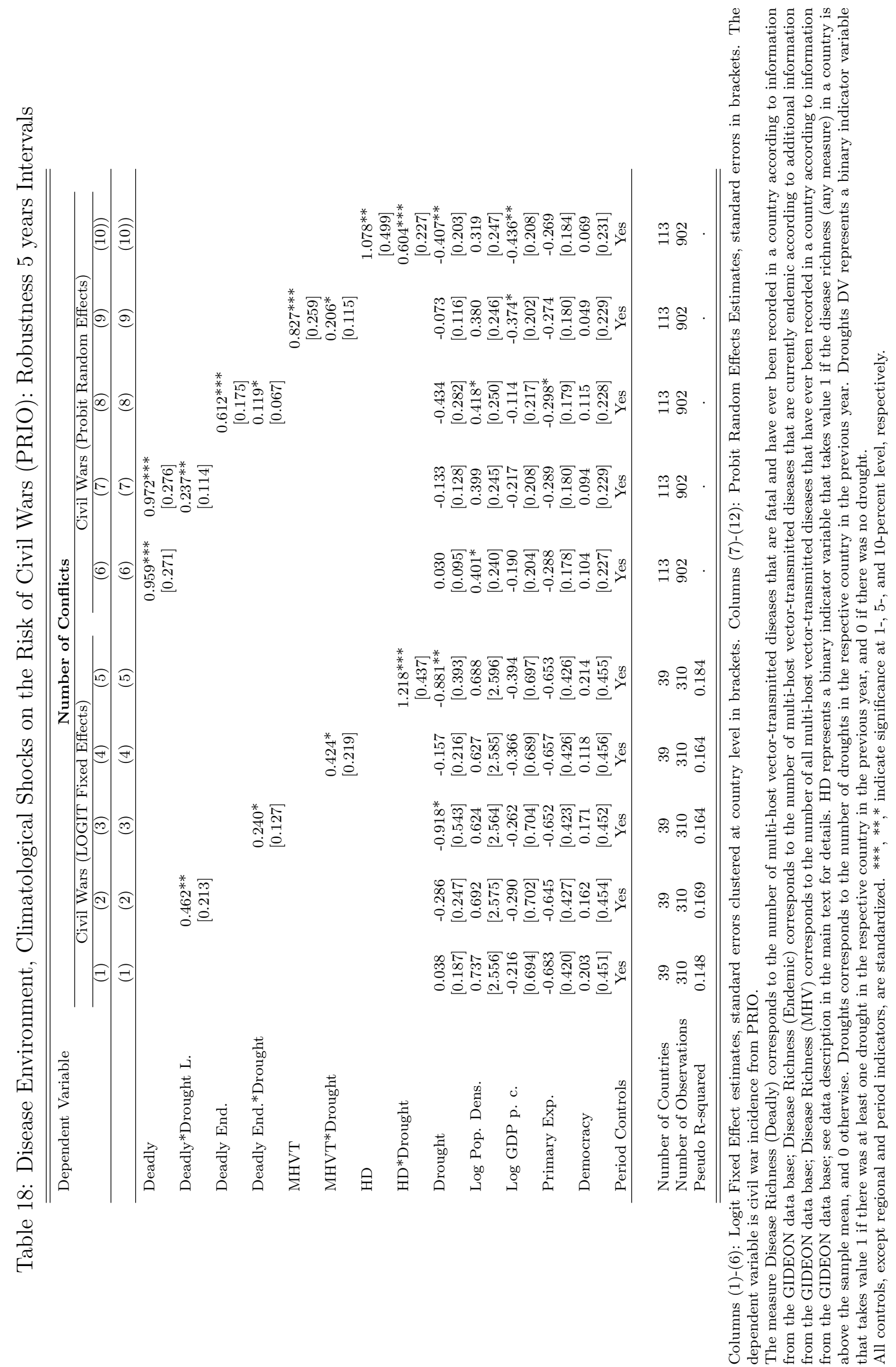


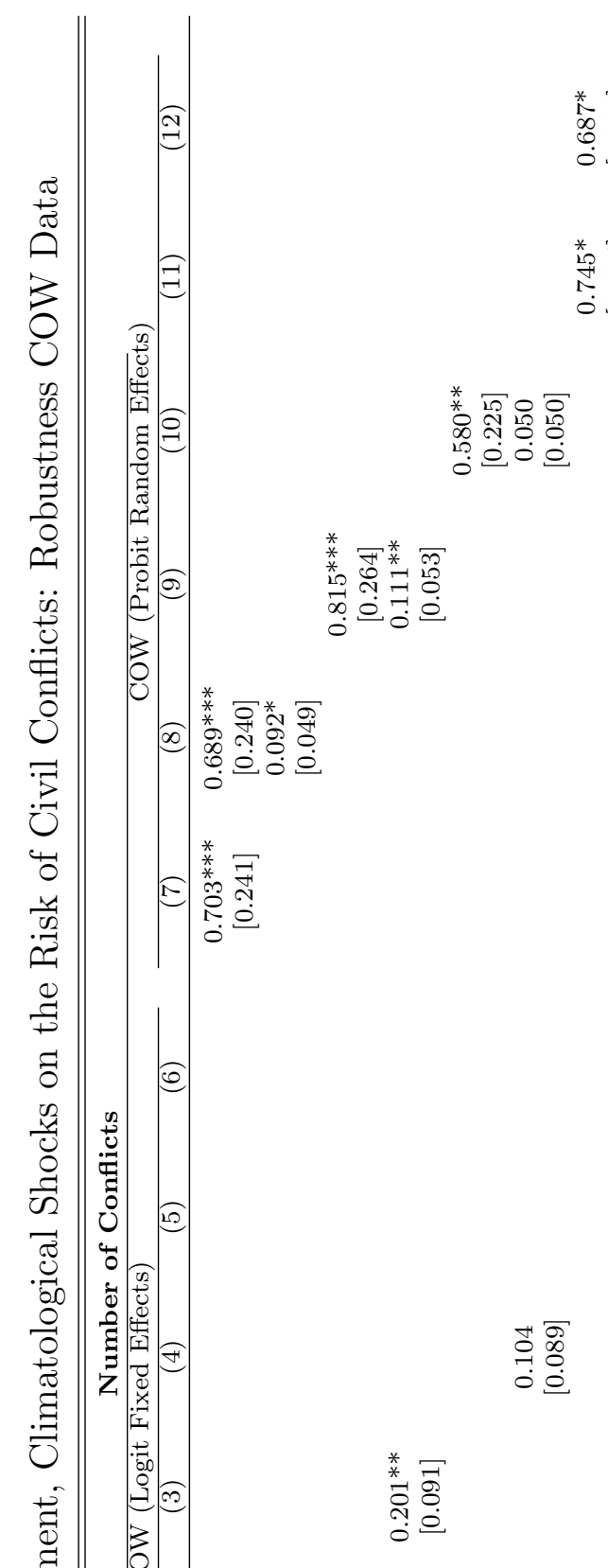

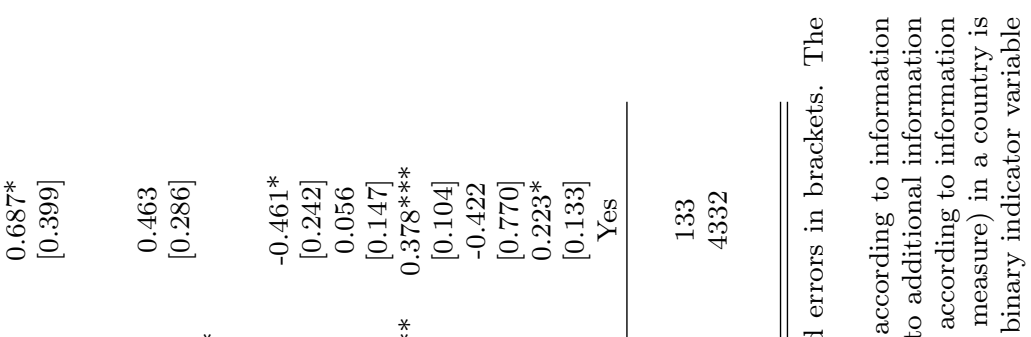

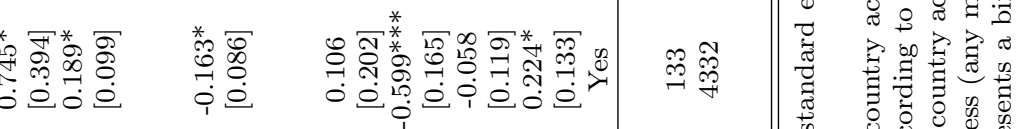

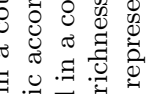

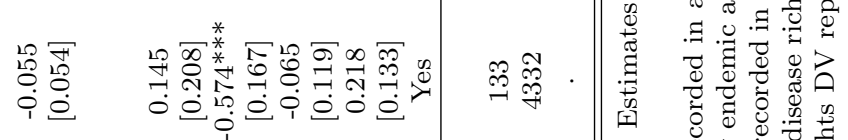
8.

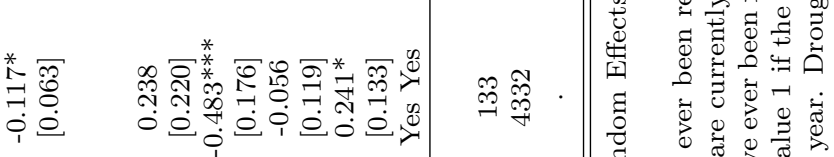

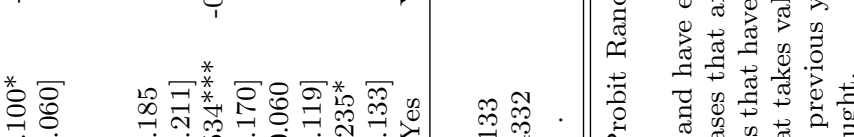

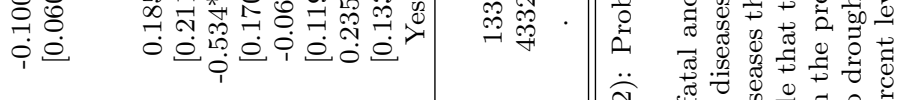

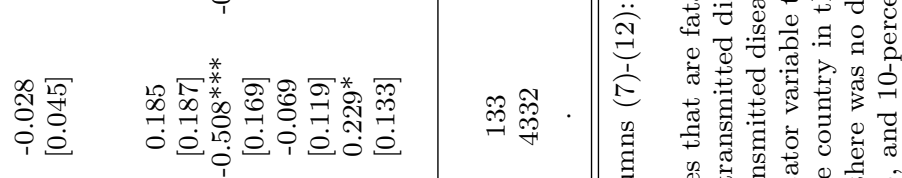

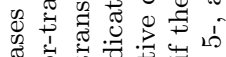
里 용

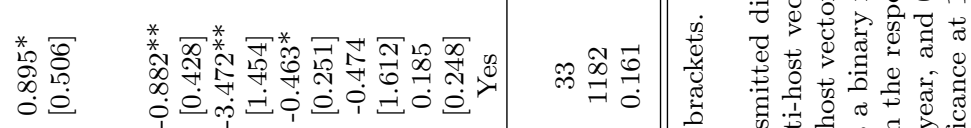

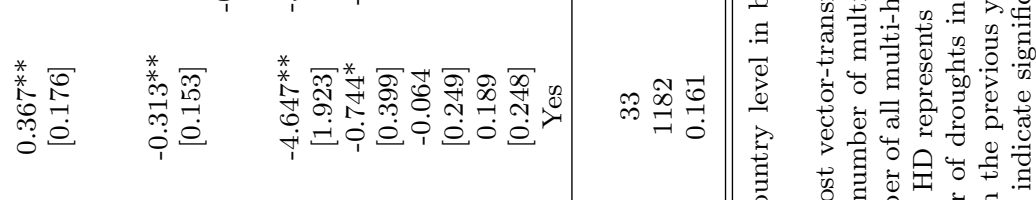

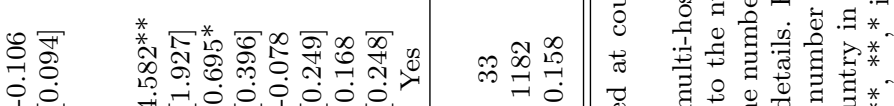

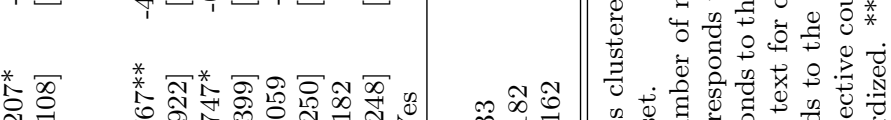

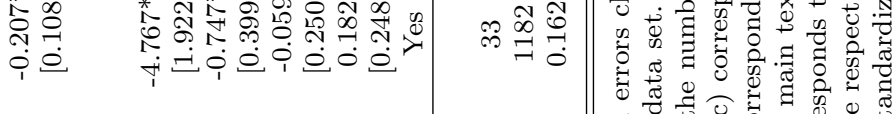

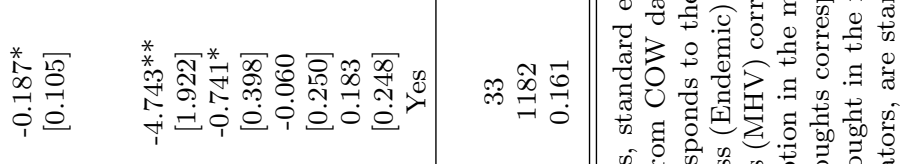

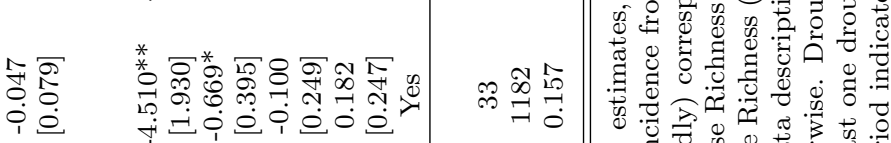

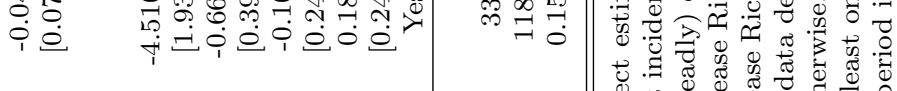

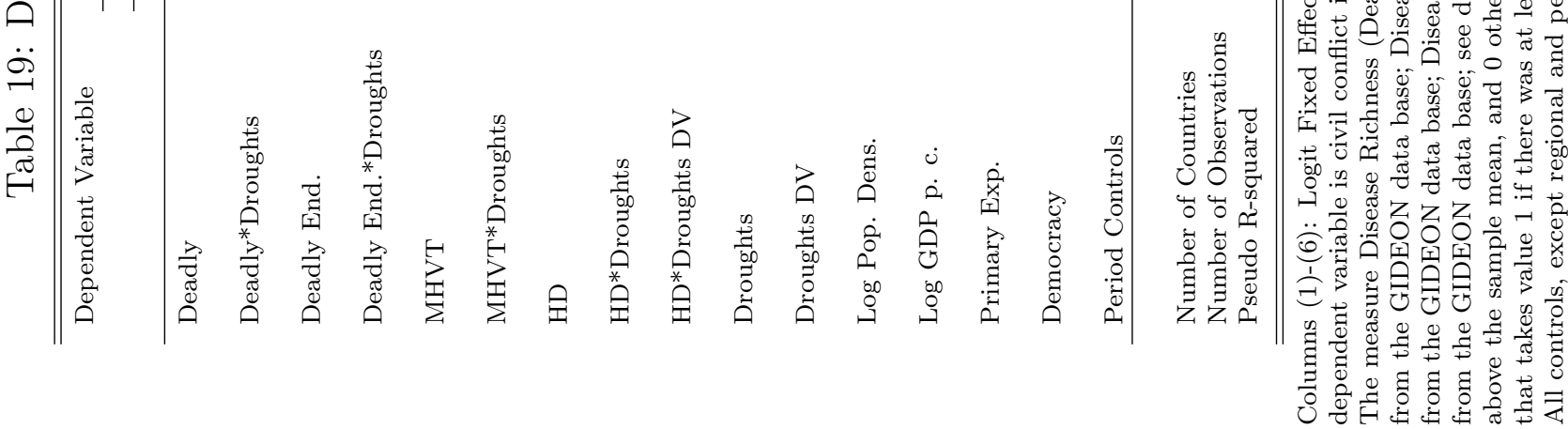

